\title{
4 Von der Bewusstseinsbildung zum kleinbäuerlichen Rohstoff (1977-1984)
}

\subsection{Die EvB und die OS3: Bücher und Nahrungsmittel}

In der Zeit, in der die OS3 von der EvB konzipiert und ins Leben gerufen wurde, erschien das Buch zum Thema Welternährung, das Anne-Marie Holenstein mit Jonathan Power verfasst hatte. ${ }^{1}$ Die Recherche für das 1976 publizierte Werk fand bereits im Sommer 1974 statt, während der Welternährungskrise und zur Zeit des Gipfels der UNO-Organisation FAO, der in Rom stattfand. Am Gipfel, auf dem sich viele Dritte-Welt-NGOs trafen oder neu entstanden, hatte auch Anne-Marie Holenstein teilgenommen. ${ }^{2}$ Das Jahr 1974 sollte eine Wende bedeuten für die Bedeutung der Landwirtschaft für die Dritte-Welt-Thematik, sowohl in der offiziellen internationalen Politik als auch auf Ebene der Nichtregierungsaktivisten. In diesem Jahr beschäftigten sich zunächst NGO-Vertreterinnen und -Vertreter und Publizisten mit dem Thema Welternährung, 1976 trug diese Beschäftigung langsam Früchte und die Thematik sickerte ins öffentliche Bewusstsein ein. 1976 erschien „How the Other Half Dies“ von Susan George, das nicht nur die NGO-Bewegung, sondern auch die öffentliche Diskussion über die Welternährung stark beeinflusste. ${ }^{3}$ George kritisierte das sogenannte Agrobusiness, die westlichen Regierungen und die neue Politik der Weltbank, die sich unterdessen vom Wiederaufbau Europas auf das Wirtschaftswachstum in der Dritten Welt verlegt hatte. ${ }^{4}$ Sie vertrat die These, dass die rechtliche Stärkung der Kleinbauern gegenüber lokalen Eliten und multinationalen Firmen in Zukunft Hungerkrisen verhindern könnten. ${ }^{5}$ Auch George war bereits zur die FAO-Konferenz von 1974 nach Rom gereist und ihr Buch zeigt auf, wie sich die europäischen Aktivistinnen und Aktivisten unterdessen vernetzt hatten. ${ }^{6}$ Unter dem Titel „What Can I Do?“ fordert George „commodity campaigns“ und beschreibt verschiedene Kampagnen, die bisher in Europa durchgeführt wurden, darunter auch die Schweizer UjamaaPulverkaffee-Aktion und die Bananenverkäufe der Frauenfelder Bananenfrauen:

1 A.-M. Holenstein-Hasler, J. Power: Hunger, sowie in Englisch J. Power, A.-M. Holenstein: World of Hunger.

2 A.-M. Holenstein-Hasler, R. Renschler, R. H. Strahm: Entwicklung heisst Befreiung, 74.

3 K. J. Kuhn: Entwicklungspolitische Solidarität, 197-202, S. George: How the Other Half Dies.

4 H. Hauser, M. Gedult von Jungenfeld: Schweiz und die Bretton-Woods-Institutionen.

5 S. George: How the Other Half Dies, 134.

6 Ebd., 11.

Ә OpenAccess. (C) 2020 Andrea Franc, publiziert von De Gruyter. (cc) BY-NC-ND Dieses Werk ist lizenziert unter der Creative Commons Attribution-NonCommercial-NoDerivatives 4.0. 
In Switzerland, one group set out to sell Tanzanian coffee, processed in Tanzania and of direct benefit to Tanzanian Ujamaa villagers; they also chose this commodity in order to publicize the unfair trade relationships between first and Third World and the role of Nestles in the control of the coffee trade. ${ }^{7}$

George nutzte hier im englischsprachigen Text den Begriff fair bzw. „unfair“. Sie war damit prägend in der Überführung des Begriffs aus dem GATT-Kontext der Verhandlungen zwischen Staaten auf die Kritik an privaten multinationalen Unternehmen wie Nestlé. Ebenfalls ist interessant, dass sie von „villagers“ spricht, von Dorfbewohnern. Damit fokussiert sie nicht, wie ursprünglich von den Initianten der Ujamaa-Pulverkaffee-Aktion intendiert, auf die industrielle Herstellung, sondern auf die kleinräumige Dorfstruktur. Erst durch diese Formulierung stützt Georg ihr im ganzen Buch vertretenes Argument der Stärkung des Kleinbauern, des „subsistent smallholder“ ${ }^{8}$ Ebenso prägend ist, dass sie die Pulverkaffee-Aktion in eine Linie mit den Bananenverkäufen setzte und nicht mehr zwischen alternativem Handel mit industriell verarbeiteten Produkten, die billiger waren als ihre in Europa hergestellten Pendants, und einem karitativen Aufpreis für Agrarrohstoffe unterschied. Damit verabschiedete sie das Postulat der Industrialisierung genauso wie die Utopie eines wirtschaftlichen Aufschliessens der Entwicklungsländer an den Westen durch alternativen Handel. Besonders hebt George hervor, dass die Bananenaktion ein "brainchild of eight housewives“ gewesen sei. ${ }^{9}$ Damit unterstreicht sie die Simplizität und Massentauglichkeit des Fair-Trade-Gedankens wie er in den 1980er-Jahren zutage trat.

Another Swiss group chose bananas to dramatize the terrible working conditions of the plantation labour force. They actually got Swiss consumers to pay $15 \mathrm{c}$ more a kilo for bananas; the chain-store distributor handed over the difference, and they contributed the funds to a worker's project in Guatemala through a Protestant church group. This project both educated consumers and was of direct usefulness to far-off producers. ${ }^{10}$

Nachdem George den Antagonismus zwischen Kleinbauern in der Dritten Welt und den westlichen Agrarkonzernen festgeschrieben hatte, folgte 1977 Frances Moore Lappé, die ebenfalls bei der FAO-Konferenz in Rom mit dabei gewesen war, mit „Food First“, das die Ernährungssouveränität in den Vordergrund rückte. ${ }^{11}$ Wie Anne-Marie Holenstein im Rückblick schreibt, räumte dieses Buch „mit den

7 Ebd., 294.

8 Ebd., 134.

9 Ebd., 295.

10 Ebd., 294.

11 F. M. Lappé, C. Fowler, J. Collins: Food First. 
Modernisierungstheorien radikal auf“. ${ }^{12}$ Sie selbst publizierte 1977 gemeinsam mit der Naturwissenschaftlerin Joan Davis in der Schweiz das Buch „Zerstörung durch Überfluss“, das Susan Georges „How the Other Half Dies“ sowie Frances Moore Lappés früheres Buch „Diet for a Small Planet“ zitiert. ${ }^{13}$ „Zerstörung durch Überfluss“ ist „Food First“ sehr ähnlich, indem es die Ernährungssouveränität propagiert und für den schweizerischen Kontext mit dem Begriff Neutralität dafür wirbt. ${ }^{14}$ Prebisch und Singers Thesen sowie die UNCTAD-Doktrin von 1964 hatten sozusagen den Höhepunkt respektive den Kulminationspunkt der „Modernisierungstheorien“ der 1950er- und 60er-Jahre gebildet. ${ }^{15}$ Nach 1974 räumten ein paar „Hausfrauen“ radikal damit auf. ${ }^{16}$

Spätestens 1974, als die FAO die UNCTAD als Referenzsystem der NGOs ablöste und eine paraakademische Literatur die zunehmend technischen ökonometrischen Artikel der Entwicklungsökonomen in den Unterlagen der Dritte-WeltAktivisten ersetzte, hatten die „Modernisierungstheorien“ für die Dritte-Welt-Bewegung ausgedient. Auffällig ist, dass aus dem 1974 formierten internationalen Netzwerk aus Aktivisten und frühen NGOs in der Folge weltweit kleine ThinkTanks wie die EvB entstanden, die wuchsen und dieses paraakademische Denken weiter stärkten. ${ }^{17}$ Vor allem Frauen wie George, Moore Lappé oder Holenstein publizierten in den Jahren nach 1974 populärwissenschaftliche Bücher, die sich gegen die grüne Revolution, gegen eine technisierte Landwirtschaft und für eine kleinräumige, kleinbäuerliche, genügsame und lokale landwirtschaftliche Produktion einsetzten. Diese Publikationen dienten als ideelle Transportmittel für die im Entstehen begriffenen Think-Tanks. Sie brachten nach 1974 die Diskussion um die Welternährung, deren Modernisierungsenthusiasmus durch „The Limits to Growth“ und „Small is Beautiful“ bereits angeschlagen war, buchstäblich wieder auf den Boden zurück. In den 1970er-Jahren wurde somit die Landwirtschaft zu einem neuen, dominanten Thema. ${ }^{18}$ Dies ging einher mit der Dominanz populär-

12 A.-M. Holenstein-Hasler, R. Renschler, R. H. Strahm: Entwicklung heisst Befreiung, 75.

13 Lappé, Frances Moore: Diet for a Small Planet (New York 1971).

14 A.-M. Holenstein, J. Davis: Zerstörung durch Überfluss, 54.

15 M. Schär: Strukturveränderungen statt Entwicklungshilfe, 22, J. Toye, R. Toye: UN and Global Political Economy, 163.

16 Zur Diskussion von „Food First“ siehe auch K. J. Kuhn: Entwicklungspolitische Solidarität, 197-202.

17 Unter anderem der Think-Tank mit dem Namen Food First, den Frances Moore Lappé 1975 mitgründete und leitete. Ihren Mitgründer Joe Collins hatte sie auf der FAO-Konferenz in Rom kennengelernt. Siehe die Webseite http://www.foodfirst.org. (12.9.2017).

18 Siehe dazu auch S. George: How the Other Half Dies, 214, K. J. Kuhn: Entwicklungspolitische Solidarität, 197-202. 
bzw. paraakademischer Bücher aus der Feder von Aktivistinnen und Aktivisten, die sich ausserhalb des akademischen Peer Reviews zum Thema äusserten.

Neben der Publikation paraakademischer Literatur für Erwachsene bauten die NGOs zudem sehr stark den Bereich der Schulbuchliteratur aus, der für manche von ihnen zu einem etablierten Standbein wurde. Im internationalen Vergleich übernahm hier wiederum die britische Oxfam eine Pionierrolle. Ab 1959 führte Oxfam eine eigene Schulabteilung, die mehrere Ausbildnerinnen und Ausbildner beschäftigte. 1963 erhielt Oxfam von der Unesco den Auftrag, eine Schulbuchserie zum Thema Welthunger zu produzieren. ${ }^{19}$ Auch in der Schweiz gaben Hilfswerke Unterrichtsmaterialien heraus, so etwa im Jahr der Welternährungskrise 1974 eine Lerneinheit zu Dürren und Hunger in der Sahelzone, die Lehrer anhielt, an ihren Schulen Spendenaktionen $\mathrm{zu}$ organisieren. ${ }^{20}$ Die EvB stiess über ein wissenschaftliches Projekt Roy Preiswerks von 1971 auf die Schulbuchliteratur. ${ }^{21}$ In diesem Projekt untersuchten Preiswerk und sein Team, zu dem auch die spätere EvB-Sekretärin Regula Renschler gehörte, europäische Lehrmittel hinsichtlich der Frage, ob sie rassistisch waren. ${ }^{22}$ Daraus entstand 1981 eine Kinderbuchreihe unter der Ägide der EvB. ${ }^{23} 1978$ arbeitete die EvB ähnlich wie Oxfam mit Unicef zusammen. Die EvB war mit der Zusammenstellung von Schulmaterial betraut, das die Unicef in den folgenden Jahren verbreiten würde. ${ }^{24}$ Interessant sind in diesem Zusammenhang wiederum der fliessende Übergang vom ursprünglichen Thema Rassismus zum Thema Landwirtschaft und das Erscheinen des Kleinbauern in den Notizen und publizierten Unterlagen. So plante Renschler denn bereits 1975 für eine Lehrerfortbildung das Thema „Drei Dörfer“ ein: Bauernfamilien aus drei Dörfern in verschiedenen Weltregionen wurden miteinander verglichen. ${ }^{25}$ Implizit stellte Renschler damit Kleinbauern in der

19 M. Black: Oxfam the First 50 Years, 102.

20 Rauh, Felix: Tierkadaver im Wüstensand. Zur Visualisierung des Hungers in der Sahelzone 1973/74, in: Angela Müller, Felix Rauh (Hg.): Wahrnehmung und mediale Inszenierung von Hunger im 20. Jahrhundert (Basel 2014) 155-176, 168.

21 A.-M. Holenstein-Hasler, R. Renschler, R. H. Strahm: Entwicklung heisst Befreiung, 105.

22 Preiswerk, Roy; Perrot, Dominique: Ethnocentrisme et histoire. L'Afrique, l'Amérique indienne et l'Asie dans les manuels occidentaux (Paris 1975).

23 Die Kinderbuchreihe Baobab, siehe http://www.baobabbooks.ch/ (24.4.2018).

24 A.-M. Holenstein-Hasler, R. Renschler, R. H. Strahm: Entwicklung heisst Befreiung, 223-236. Siehe auch SozArch, EvB, Ar 430.17.5. Handakten Regula Renschler: Kinder und Dritte Welt (I). SozArch, EvB, Ar 17.6. Handakten Regula Renschler: Kinder und Dritte Welt (II). SozArch, EvB, Ar 430.91.2. Handakten Regula Renschler: Nachlieferung 2009, Teil 2.

25 SozArch, EvB, Ar 430.17.6. Handakten Regula Renschler: Kinder und Dritte Welt (II). SozArch, EvB, Ar 430.91.2. Handakten Regula Renschler: Nachlieferung 2009, Teil 2. Lehrerfortbildung/ Kurse Kanton Bern, Lektionenreihe „Drei Dörfer“, 1975-1978. 
Schweiz und in Spanien auf dieselbe Stufe mit Kleinbauern in Guatemala. Auf der Ebene des Schulunterrichts fand somit das Herunterbrechen der oben erwähnten populärwissenschaftlichen Studien zur Ernährungssouveränität auf die Figur des Kleinbauern statt. Diese Unterlagen wurden später wiederum von der UmweltNGO WWF, die ihrerseits ebenfalls einen Lehrerservice unterhielt, übernommen. ${ }^{26}$ Auf der Ebene des Schulunterrichts wird somit sehr früh und am besten sichtbar, wie die Reduktion der komplexen Thematik des Nord-Süd-Handels auf die Figur des Kleinbauern erfolgte und damit eine vermeintliche Gleichheit und Solidarität zwischen Kleinbauern aller Welt sowie eine Diskursbrücke zum Umweltschutz entstand.

Diese aktivistischen Frauen und paraakademischen Think-Tanks stellten sich gegen das Agrobusiness, das sich im Rahmen der Grünen Revolution als neuer Gegner präsentierte, und zunehmend auch gegen die Politik von internationalen Organisationen wie etwa der Weltbank und der FAO. 1974 wird eine Praxisänderung in der Haltung der Entwicklungs-NGOs ersichtlich: Während sie bisher internationale Organisationen wie die UNCTAD, den IWF oder gewisse GATT-Entscheide unterstützt hatten, lehnten sie nun die Politik einer UNO-Organisation wie der FAO ab. ${ }^{27}$ Nach 1974 traten NGOs nicht mehr als Advokaten der UNCTAD oder gar des GATT in der Öffentlichkeit auf, sondern als eigenständige Akteure. Als neue Alternative vertrat die NGO-Gemeinschaft zunehmend das Modell des biologischen Landbaus aus der Hand der Kleinbauernfamilie oder der Genossenschaft, wie es die zahlreichen oben aufgeführten populärwissenschaftlichen Publikationen zum Thema Welternährung propagierten. Während die EvB zuhause in der Schweiz die Ujamaa-Pulverkaffee-Aktion noch 1975 ein letztes Mal durchführte und daraufhin 1976 mit der Jutesack-Aktion auf die Handarbeit und die natürlichen Rohstoffe wie die Jutefaser umschwenkte, begann in Rom 1974 bereits die Fokussierung auf die Landwirtschaft und den Kleinbauern.

Nach 1975 kümmerte sich die EvB als entwicklungspolitischer Think-Tank zunehmend um die nationale und globale Agrarpolitik. Die Aufgabe der 1977 gegründeten Firma OS3 bestand derweil darin, tropische Rohstoffe von Kleinbauern aus Entwicklungsländern einzuführen, um das lokale Schweizer Angebot zu ergänzen. Die OS3 übernahm somit die Umsetzung des Kleinbauernmodells in der Praxis. Ihre Aufgabe bestand nun sehr rasch nicht mehr darin, für das eigentliche Bewusstsein zu sorgen, sondern die Waren für die bewusste Kundschaft zu liefern. Die „Information über das betreffende Produkt, seine Herkunft und

26 A.-M. Holenstein-Hasler, R. Renschler, R. H. Strahm: Entwicklung heisst Befreiung, 234. 27 Bodleian Library, Oxford. Oxfam archive, MS, Oxfam. COM/3/1/12. Folder 3: Haslemere Declaration. 
Preiszusammensetzung, die Umstände seiner Entstehung oder Gewinnung, sowie die Situation des Exportgebietes“, wie es die Statuten der OS3 vorsahen, trat in den Hintergrund und machte dem eigentlichen Produkt Platz. ${ }^{28}$ Die „Information“ wurde implizit. Wer Produkte im Dritte-Welt-Laden kaufte, hatte das „Bewusstsein“ bereits erlangt und hing dem Konzept des selbstgenügsamen Kleinbauern an. So machte sich Martin Blum als frisch eingestellter Geschäftsführer der OS3 auf die Suche nach geeigneten Lieferanten in Ländern des Südens. ${ }^{29}$ Damit war das Ende der aktiven Rolle der Entwicklungsländer, wie sie noch bei der UNCTAD um 1964 erkennbar gewesen war, gegen Ende der 1970er-Jahre besiegelt. Aus aussenpolitischen Quellen der Bundesverwaltung geht hervor, dass sich in den 1960er-Jahren Anbieter aus der Dritten Welt in der Schweiz präsentierten und damals eine kritische Nichtregierungsinstanz sehr gebraucht hätten. ${ }^{30}$ Die OS3 kam zu spät und fokussierte auf Rohstoffe und nicht auf die Produkte, welche Entwicklungsländer im Angebot hatten, wie etwa Textilien oder gar Möbel. ${ }^{31}$ So stellten etwa verschiedene Botschaften von Entwicklungsländern bereits ab Mitte der 1960er-Jahre in der Schweiz Anträge auf Zollpräferenzen für diverse Produkte. Diese Anträge wurden von der Bundesverwaltung zunächst verschleppt und in vielen Fällen schliesslich abschlägig beantwortet. ${ }^{32}$ Als die OS3 gegründet wurde, war das Zollpräferenzgesetz in der Schweiz bereits seit fünf Jahren in Kraft und die Aufbruchstimmung unter den Entwicklungsländern, die in den 1960er-Jahren noch Hoffnung in Anträge der Botschaften gesetzt hatten, vorüber. Anstatt die Ausführungsbestimmungen im Zollpräferenzgesetz zu hinterfragen und aktiv etwa auf die Botschaften der Entwicklungsländer in der Schweiz zuzugehen, interessierte sich die OS3 nach ihrer Gründung nicht einmal mehr für Produkte, die im Schweizer Gesetz für Zollpräferenzen zugelassen gewesen wären. ${ }^{33}$ Stattdessen machte sie sich aktiv auf die Suche nach Lieferanten in Entwicklungsländern, die ihrem Konzept und damit der Schablone des Kleinbauern entsprachen und lediglich die klassischen kolonialen Nahrungsrohstoffe produzierten. ${ }^{34}$ Die Bereitschaft, auf die Vertreter der Entwicklungsländer zu hören und ihre Anliegen

28 SozArch, Claro 1011.1. OS3 Statuten, Bern, 22.6.1977. Siehe dazu auch R. Quaas: Fair Trade, 239. 29 SozArch, Claro 1010.2. OS3 Gründung: Korrespondenz 1974-3.1977. SozArch, Claro 5451. Food Produzenten Bolivien: El Ceibo/Kakao 1978 - 1996. SozArch, Claro 5452.11. El Ceibo (Sapecheo, La Paz, Bolivien)/Kakao: Produzentensuche, PAK-Vorlagen, Korrespondenz; 1978-1996.

30 S. Huber: Handelshemmnisse gegenüber Entwicklungsländern.

31 SozArch, EvB, Ar 430.41.1. Mappe 3: Ein entwicklungspolitisches Label - Chancen und Probleme, Ch. Lanz, 1983.

32 S. Huber: Handelshemmnisse gegenüber Entwicklungsländern.

33 So insbesondere Textilien.

34 Siehe dazu Claro Orpund. Claro 5452.11. El Ceibo (Sapecheo, La Paz, Bolivien)/Kakao: Produzentensuche, PAK-Vorlagen, Korrespondenz; 1978-1996. 
aufzunehmen, war nach einer kurzen Aufbruchzeit in den 1960er-Jahren verschwunden. Es war im Gegenteil so, dass die OS3 in schriftlichen Grundsätzen festhielt, welche Produzenten aus Entwicklungsländern in Frage kamen. ${ }^{35}$

Von der EvB vorgegeben hatte die OS3 somit eine Schablone, die einzig Produzenten zuliess, die dem in den späten 1970er-Jahren vorherrschenden Weltbild entsprachen. Wie immer wieder in dieser Arbeit aufgezeigt, teilte die Dritte-Welt-Bewegung ihr Weltbild mit den Neokonservativen, welche ebenfalls „decentralization“, „farmer's cooperatives“ und „self-sufficiency“ auf ihre Fahne geschrieben hatten. ${ }^{36}$ Gerade die Überschneidung mit dem neokonservativen Weltbild zeigt auf, wie stark sich die EvB als Think-Tank bereits Ende der 1970erJahre von der akademischen Ökonomie entfernt hatte und im Falle der Schweiz einen impliziten Konsens mit der nationalkonservativen Politik praktizierte.

Ein weiteres Beispiel, das aufzeigt, wie sich die EvB und die OS3 bzw. die populärwissenschaftliche Theorie der Think-Tanks und die Praxis der neuen alternativen Handelsfirmen ergänzten, ist das zweite Fair-Trade-Produkt der EvB: die Jutetasche. Anne-Marie Holenstein schreibt, dass das 1977 erstmals erschienene und danach mehrfach aufgelegte Buch „Zerstörung durch Überfluss“ den Verkauf von Jutetaschen ergänzt habe. ${ }^{37}$ Diese Studie war als Arbeit der Gruppe „Landwirtschaft und Ernährung“ an der Universität Zürich entstanden. Holenstein gab die Publikation mit der ETH-Dozentin Joan Davis heraus. Gemäss Ursina Eichenberger waren die beiden Zürcher Hochschulen ab 1970 ein Epizentrum der Umweltbewegung. ${ }^{38}$ Vertreterinnen und Vertreter der EvB, die in Zürich an entsprechenden Seminaren teilnahmen, griffen die Thesen der Umweltbewegung auf und integrierten sie in ihre Arbeit bei der EvB. ${ }^{39}$ Diese Beobachtung schwächt etwas die hier bis anhin vertretene These, dass der Wandel im Fair-Trade-Konzept mit einer Ent- oder Paraakademisierung einherging, denn dies war nur bedingt der Fall. In einer ersten Phase der Entakademisierung der Dritte-Welt-NGOs verlagerte sich die Zusammenarbeit: Statt mit akademischen Ökonomen wurde nun mit akademischen Naturwissenschaftlern zusammengearbeitet, die sich aus ihrer Sicht zum Nord-Süd-Handel äusserten. Zunächst ist also nur von einer Entakademisierung im Fachbereich der Wirtschaftswissenschaften zu sprechen. Zu den ausserwissenschaftlich aktiven Naturwissenschaftlern gehörte etwa Theo Ginsburg, ETH-Professor und Atomkraftgegner der ersten Stunde, oder Joan Davis, die

35 SozArch, Claro 1011.1. OS3 Gründung: Grundsätze der Geschäftspolitik, Juni 1977.

36 W. Röpke: The Social Crisis.

37 A.-M. Holenstein-Hasler, R. Renschler, R. H. Strahm: Entwicklung heisst Befreiung, 194.

A.-M. Holenstein, J. Davis: Zerstörung durch Überfluss.

38 U. Eichenberger: Ökologie und Selbstbestimmung, 2.

39 Ebd., 59-60. 
ebenfalls an der ETH Zürich lehrte. In dieser akademischen, wachstumskritischen Bewegung war auch Pierre Fornallaz aktiv. Er wirkte ab 1968 als Professor an der ETH, war ein Pionier der Solartechnologie und entwickelte selbst den Begriff der „ökologischen Wirtschaft“. ${ }^{40}$ Mit E.F. Schumacher, dem Autor von „Small is Beautiful“, lud er sozusagen einen „abtrünnigen“ Ökonomen nach Zürich ein. Schumacher leitete an der ETH unter anderem einen ganztägigen Workshop. 1973 fand unter Fornallaz' Leitung in Zürich das Symposium „Technik für oder gegen den Menschen statt“. ${ }^{41}$ Die Nord-Süd-Bewegung ersetzte den akademischen Kontakt zu Ökonomen durch jenen zu Naturwissenschaftlern. Sie unterlegte also ihr Konzept eines gerechten Nord-Süd-Handels in den 1970er-Jahren neu mit akademischen Resultaten aus den Naturwissenschaften. Vor diesem Hintergrund ist es denn nicht erstaunlich, dass die EvB sich für ökologische Landwirtschaft in Entwicklungsländern einsetzte und dass die OS3 einzig tropische Rohstoffe nachfragte. Aus naturwissenschaftlicher bzw. ökologischer Sicht schien es Sinn $\mathrm{zu}$ machen, lokal zu produzieren, keine weitere Industrialisierung oder lange Transportwege zu unterstützen und einzig tropische Rohstoffe aus Entwicklungsländern zu importieren. Aus ökonomischer Sicht war dieser Ansatz in Bezug auf die Nord-Süd-Handelsbeziehungen jedoch ungerecht und für manche Länder fatal. ${ }^{42}$ Der inhärente Widerspruch zwischen Ökologie und ökonomischer Fairness wurde jedoch von der NGO-Bewegung nicht mehr wahrgenommen, da der Kontakt zur akademischen Ökonomie unterdessen abgebrochen war.

Gemäss Eichenberger wirkte die aus Naturwissenschaftlerinnen und -wissenschaftlern bestehende Arbeitsgemeinschaft Umwelt (AGU) in Zürich als treibende Kraft beim Aufbau des biologischen Landbaus in der Schweiz. ${ }^{43}$ Mit dabei war auch die EvB als Teil dieser Bewegung. Die Diskursbrücke war über das Thema Fleischverzicht erfolgt und kulminierte erstmal in der Kritik an Futtermittelimporten. Um sich argumentativ aufzurüsten nahmen etwa Vertreter der EvB an einem Seminar der AGU 1973 teil. ${ }^{44}$ Bei der EvB setzte sich Anne-Marie Holenstein nicht nur auf nationaler, sondern auch auf internationaler Ebene für die kleinbäuerliche und ökologische Landwirtschaft ein. So gehörte sie für die Schweizer NGO-Szene der International Peace Research Association (IPRA) um Johan Galtung an und stand der Food Policy Study Group der IPRA sogar als

40 Ebd., 25, Fornallaz, Pierre: Die ökologische Wirtschaft. Auf dem Weg zu einer verantworteten Wirtschaftsweise (Aarau etc. 1986).

41 U. Eichenberger: Ökologie und Selbstbestimmung, 27.

42 J. Bhagwati: Trade Liberalisation.

43 U. Eichenberger: Ökologie und Selbstbestimmung, 23.

44 Ebd., 59-60. 
Koordinatorin vor. ${ }^{45}$ So war Holenstein und damit die EvB im Bereich Landwirtschaft in der internationalen NGO-Szene bestens vernetzt. Anne-Marie Holenstein hatte bereits 1974 an der FAO-Konferenz in Rom Kontakte zu NGOs geknüpft, 1979 reiste sie offiziell als IPRA-Koordinatorin nach Rom zu einer weiteren FAO-Konferenz. Gemäss Kuhn war die EvB Pionierin einer kritischen Teilnahme an Weltkonferenzen und damit eine der Vorläuferinnen der Myriaden von Nichtregierungsorganisationen an den Konferenzen der 1990er Jahre. ${ }^{46}$ Ein Interesse an der UNCTAD der 1970er- und 80er-Jahre, die als internationale Konferenz für einen fairen Nord-Süd-Handel zuständig war, ist in den Akten der EvB nicht belegbar. Hatten die UNCTAD-Konferenzen von 1964 und 1968 noch massgeblich zur Gründung der westlichen Dritte-Welt-Bewegung beigetraten und deren Forderungen vorgegeben, verschwand diese internationale Konferenz von der Agenda der NGOs, und damit kamen auch Forderungen der ersten Konferenz von 1964 abhanden. Dies hatten sich nicht zuletzt die Entwicklungsländer selbst zuzuschreiben, da sie die UNCTAD nicht als ihre geschlossene und fordernde Stimme erhalten konnten. Mit dem Weggang Prebischs als Generalsekretär der UNCTAD 1969 begann eine Phase der „Frustration für die Bestrebungen der Entwicklungsländer“. ${ }^{47}$ Während die UNCTAD Mitte der 1970er-Jahre und spätestens mit dem Anlaufen der Vorbereitungen für eine Überführung des GATT in die WTO in der Bedeutungslosigkeit versank, erfolgte gleichzeitig eine Bedeutungszunahme der FAO, die sich der Landwirtschaft und der Produktion von Nahrungsmittelrohstoffen widmete. ${ }^{48}$ Sie wurde zu jener internationalen Organisation, welche die Agenda der NGOs in den 1970er-Jahren bestimmte.

Nach der Konferenz von 1974 nahm die FAO das Thema Kleinbauern vorsichtig auf. ${ }^{49} 1979$ fand dazu in Rom, dem Sitz der FAO, die FAO-Konferenz zur ländlichen Entwicklung und Agrarreform statt. Anne-Marie Holenstein nahm wie erwähnt als Koordinatorin der IPRA an einer Begleitkonferenz der NGOs teil. Mit dabei waren auch Frances Moore Lappé, die Autorin von „Food First“, und Joe Collins, mit dem Lappé den Think-Tank Food First gegründet hatte. Moore Lappé, Collins und Susan George waren unterdessen mit Holenstein bekannt und vernetzt. ${ }^{50}$ Diese Vertreterinnen und Vertreter der verschiedenen neuen Think-Tanks

45 Siehe dazu http://www.iprapeace.org/ (13.3.2018).

46 K. J. Kuhn: Entwicklungspolitische Solidarität, 257-258.

47 J. Toye, R. Toye: UN and Global Political Economy, 233.

48 Ebd., 272.

49 C. Gerlach: Famine Responses.

50 SozArch, EvB, Ar 430.91.6. Handakten Anne-Marie Holenstein: IPRA Food Policy Study Group und World Conference on Agrarian Reform and rural Development (WCARRD), 1979. 
präsentierten als Rome Declaration Group Gegenthesen zur FAO. ${ }^{51}$ In der Haltung der Rome Declaration Group wird der Wandel des Konzepts, das ursprünglich auf den Prebisch-Singer-Anliegen von 1964 beruhte und die Grundlagen für den Ujamaa-Pulverkaffee-Verkauf (der letztmals noch 1975 durchgeführt wurde) lieferte, sehr deutlich. Klar wird auch, dass hier eine international vernetzte Bewegung mit einer Stimme sprach und dass die Schweizer Bewegung im Strom dieses Konzeptwandels mitgetragen wurde. Die Gruppe präsentierte zwölf Thesen, zum Handel schrieb sie:

Das falsche Versprechen: Zunahme des Handels ist Fortschritt. Die ländlichen Ökonomien der Entwicklungsländer müssen darum durch Handel mit dem Weltwirtschaftssystem verbunden werden..$^{52}$

Damit brach die Bewegung schriftlich mit der UNCTAD-Doktrin. Diese hatte genau dies gefordert: dass die Entwicklungsländer durch Handel stärker ins Weltwirtschaftssystem eingebunden werden, daher der Slogan Trade, not Aid. Das Konzept von Handel (statt Hilfe) hätte den Fortschritt bzw. die Modernisierung nach sich ziehen sollen. Doch diese Modernisierung wurde zunehmend in Frage gestellt und nun, Ende der 1970er-Jahre, schriftlich verabschiedet.

Die Aktivistinnen und Aktivisten postulierten, sie würden die Konzepte der Regierungen und internationalen Organisationen kritisieren, dabei stellten sie sich gegen ihre eigenen Überzeugungen von früher, die in den internationalen Organisationen und ansatzweise auch in den nationalen Regierungen zumindest vordergründig umgesetzt wurden. Dieser Konzeptwandel war innerhalb der Bewegung zu langsam und scheinbar so kohärent vonstattengegangen, dass er nicht als Bruch mit der eigenen Vergangenheit wahrgenommen wurde. Nur selten, etwa im weiter oben zitierten Text von Strahm, wies jemand mit dem Hinweis auf seine eigene Vertretung der These der „Abkopplung“ auf einen theoretischen Wandel hin. ${ }^{53}$

Gleichwohl ging der Konzeptwandel in der Dritte-Welt-Bewegung so schnell voran, dass die Privatwirtschaft trotz ihrer Bereitschaft, sich auf Konsumentenwünsche einzustellen, nicht mithalten konnte. So sagte etwa der Migros-Präsident Pierre Arnold im Rahmen der Aktion M-Frühling 1980 genau das, was die DritteWelt-Bewegung ursprünglich gefordert hatte: Dass die Migros den Ländern der

51 K. J. Kuhn: Entwicklungspolitische Solidarität, 257-258. Siehe auch zu den ersten Gegenthesen von 1974 S. George: How the Other Half Dies, 11.

52 A.-M. Holenstein-Hasler, R. Renschler, R. H. Strahm: Entwicklung heisst Befreiung, 181.

53 Siehe Kapitel 3.7. Die Schweizer Bergbauern: die Peripherie im Inland sowie R. H. Strahm: Beziehungen Schweiz Dritte Welt, 9. 
Dritten Welt helfen wolle, indem sie ihre Erzeugnisse kaufe. ${ }^{54}$ Er wiederholte praktisch wörtlich die Forderungen, die die EvB im Kontext der Ujamaa-Pulverkaffee-Kampagne vorgebracht hatte. Unterdessen hatte sich die Dritte-Welt-Bewegung aber bereits wieder von dieser Forderung entfernt. Im Jahr 1980 widersprach Anne-Marie Holenstein dem Migros-Präsidenten im Namen der EvB. Sie brachte vor, der Profit liege bei den Grossgrundbesitzern und den internationalen Konzernen, und unter solchen Rahmenbedingungen sei der Kauf von Agrarprodukten aus Entwicklungsländern keine Hilfe..$^{55}$ Die Abkehr von den ursprünglichen Grundsätzen eines gerechten Nord-Süd-Handels zeigte sich nicht nur in der theoretischen Diskussion bei der EvB, sondern auch in der Praxis bei der OS3. Knappe drei Jahre nach der Gründung, zur Zeit des Migros-Frühlings im Jahr 1980, legte sich die Firma neue Grundsätze zu. Bei der Gründung im Juni 1977 war noch Folgendes beschlossen worden: „Eine Weitergabe der Produkte an vorwiegend kommerziell orientierte Weiterverkäufer ist ausgeschlossen. "56 Bereits im November 1979 verfasste die OS3 ein neues Papier, in dem sie ihre Gesellschafter fragte: „Soll die OS3 in den breiteren Handel vorstossen?“57 Langsam verabschiedete sich die Firma von der Utopie eines alternativen Handelssystems. Auch wenn dies vordergründig als Konflikt wahrgenommen wurde, fand in Tat und Wahrheit eine Annäherung zwischen den Grossverteilern und dem Bereich des alternativen Handels statt, welche langfristig den Verkauf von Produkten mit Gütesiegel in Schweizer Supermärkten ermöglichte.

Während sich der alternative Handel langsam auf den Massenkonsum eines beschränkten Warenkorbs tropischer Nahrungsrohstoffe hinbewegte, lieferte die EvB die ideelle Legitimationsbasis für diesen Wandel. Wie „Food First“ räumte auch das Buch „Zerstörung durch Überfluss“ mit der bisherigen Doktrin radikal auf. ${ }^{58}$ Anne-Marie Holenstein war zu einer vom WWF finanzierten Arbeitsgruppe von Zürcher Naturwissenschaftlern gestossen. „Zerstörung durch Überfluss“ war eine Publikation dieser Arbeitsgruppe, finanziert wurde sie durch den Tierschutzverband, herausgegeben von Anne-Marie Holenstein und der ETH-Dozen-

54 A.-M. Holenstein-Hasler, R. Renschler, R. H. Strahm: Entwicklung heisst Befreiung, 209-210, B. Mahler: ,umdenken - umschwenken'.

55 A.-M. Holenstein-Hasler, R. Renschler, R. H. Strahm: Entwicklung heisst Befreiung, 211. Siehe auch SozArch, EvB, Ar 430.30.3. MIGROS 1979-1984.

56 SozArch, Claro 1011.1. OS3 Statuten, Bern, 22.6.1977.

57 SozArch, Claro 1010.12. OS3 Gründung: Mario Carera, OS3 bald im breiteren Handel?, November 1979.

58 F. M. Lappé, C. Fowler, J. Collins: Food First, A.-M. Holenstein, J. Davis: Zerstörung durch Überfluss. 
tin Joan Davis und vertrieben von der EvB, den Dritte-Welt-Läden und der KAG. ${ }^{59}$ Zunächst brach das Buch mit den Wirtschaftswissenschaften, indem es die internationale Arbeitsteilung wie auch die Prebisch-Singer-These ad absurdum führte. ${ }^{60}$ Danach stellte es unmissverständlich die Forderung nach agrarpolitischer Autarkie und der Einführung neoprotekionistischer Massnahmen. ${ }^{61}$ Wirtschaftswachstum bzw. die Produktivität wurde dabei als Grundproblem benannt: „Man geht darum das Problem verkehrt an, wenn man behauptet, die Produktivität der Landwirtschaft sei zu klein. Vielmehr ist die Produktion der übrigen Wirtschaft zu gross. “62

Kurz gesagt: Der Grundsatz, Entwicklungsländern Waren abzukaufen, war dem Grundsatz gewichen, lieber in der Schweiz einzukaufen, als das Agrobusiness zu unterstützen. Der Fokus auf ökologische, lokale Produktion machte aus ökonomischer Sicht den Weg frei für eine klare Kehrtwende in der Handelspolitik. So begann die Bewegung Ende der 1970er-Jahre staatliche Subventionen an die Landwirtschaft zu unterstützen. ${ }^{63}$ Dass sie damit einen staatlichen Eingriff unterstützte, der noch fatalere ökonomische Auswirkungen hatte als Importzölle, da ein Entwicklungsland hier nicht einmal mehr Zollpräferenzen beantragen konnte, wurde nicht thematisiert. Während sich Ökonominnen und Ökonomen weiterhin aus entwicklungspolitischer Sicht gegen westliche Agrarsubventionen einsetzten und das GATT weiterhin offiziell die Politik vertrat, dass Importzölle immerhin Subventionen vorzuziehen seien, sprach sich nicht nur die Bio-Bewegung, sondern mit der EvB auch die Dritte-Welt-Bewegung dafür aus, dass es in gewissen Fällen Agrarsubventionen geben solle. Nicht in der Höhe der Schweizer Agrarbeiträge sah die Bewegung ein Problem, sondern in ihrer Verwendung. Anstatt an Grossbetriebe sollte das Geld an Kleinbetriebe gehen, die nach ökologischen Kriterien wirtschafteten. ${ }^{64}$ Mit der Unterstützung von Agrarsubventionen kehrte die Bewegung ihre ursprüngliche Stossrichtung ins Gegenteil und verstärkte diese gar noch. Auch wenn akademisch arrivierte Naturwissenschaftlerinnen und -wissenschaftler zur Bewegung gehörten, muss man davon ausgehen, dass diese die wirtschaftswissenschaftliche Handelstheorie offensichtlich nicht kannten. So haben Naturwissenschaftler den Abschied von der Makroökonomie sozusagen akademisch begleitet. Die Kluft, die sich zwischen den Wirtschaftswissenschaften

59 Ebd., 5.

60 Ebd., 72.

61 Ebd., 57.

62 Ebd., 64.

63 Ebd., 53.

64 U. Eichenberger: Ökologie und Selbstbestimmung, 61. 
und der Dritte-Welt-Bewegung in den 1970er-Jahren öffnete, wurde somit von Naturwissenschaftlerinnen und -wissenschaftlern anfänglich mitverursacht.

\subsection{Der Kleinbauer als gemeinsamer politischer Nenner: ein Bio-Gütesiegel 1981, die Futtermittelinitiative und die Kleinbauerninitiative}

Mit 93 Prozent Zustimmung nahmen die Schweizer Bürgerinnen und Bürger 1971 den sogenannten Umweltartikel an, der damit in der Schweizerischen Bundesverfassung verankert wurde. ${ }^{65}$ Für kurze Zeit schien sich in der schweizerischen Politik eine „grosse Allianz“ für den Umweltschutz aller politischer Richtungen gebildet zu haben. ${ }^{66}$ Im gleichen Jahr entstand das Bundesamt für Umwelt, Wald und Landschaft. Umweltthemen fielen auf fruchtbaren Boden. Auch die bürgerliche Politik in der Schweiz hatte bereits zu Beginn der 1970er-Jahre die grundsätzliche Nachfrage nach Umweltschutzmassnahmen erkannt. ${ }^{67}$ Neuere Forschung zur Schweizer Geschichte der 1970er-Jahre hat denn auch gezeigt, dass etwa die Bewegung für einen biologischen Landbau zu guten Teilen von bürgerlich-konservativen Kreisen getragen wurde. ${ }^{68}$ Umgekehrt wurde gezeigt, dass die Linke in der Schweiz Umweltanliegen nicht sofort und vorbehaltlos übernommen hat. ${ }^{69}$

Die Dominanz der Umweltfrage Mitte der 1970er-Jahre manifestierte sich auf internationaler Ebene durch die beiden Bücher „The Limits to Growth“ (1972) und „Small is Beautiful“ (1973). So gab denn eigentlich die Kritik am wirtschaftlichen Wachstum der Nachkriegszeit (Limits to Growth) den Auftakt zur Umweltdiskussion, dicht gefolgt von der Rückbesinnung auf die Produktion in Klein- und Familienbetrieben und nach traditionellen Methoden (Small is beautiful). Kupper

65 Siehe dazu auf der Webseite der Schweizerischen Bundeskanzlei unter der Rubrik „Volksabstimmungen“, Bundesbeschluss vom 18.12.1970 über die Ergänzung der Bundesverfassung durch einen Artikel 24septies betreffend den Schutz des Menschen und seiner natürlichen Umwelt gegen schädliche oder lästige Einwirkungen, angenommen am 6.6.1971 (https://www.admin.ch/ ch/d/pore/va/19710606/index.html) (24.4.2018).

66 Kupper, Patrick: Die ,1970er Diagnose‘: Grundsätzliche Überlegungen zu einem Wendepunkt der Umweltgeschicht, in: Archiv für Sozialgeschichte 43 (2003) 325-348, 344.

67 B. Mahler: ,umdenken - umschwenken', 20 - 32.

68 U. Eichenberger: Ökologie und Selbstbestimmung, 15, B. Mahler: ,umdenken - umschwenken‘, 17-18, P. Kupper: Die ,1970er Diagnose‘, 344.

69 O. Wyss: Sozialismus ohne Wachstum. 
spricht von „einer Bewegung vom Grossen ins Kleine““ ${ }^{70}$ Diese zwei Aspekte (Wachstumskritik und Kleinräumigkeit) sollten innert kürzester Zeit die zwei Hauptforderungen der Dritte-Welt-Bewegung (Marktzugang und Industrialisierung) von der Agenda verdrängen und die Berechtigung dieser Forderungen angreifen.

Somit rannte der Agronom Hardy Vogtman offene Türen ein, als er zu Beginn der 1970er-Jahre Unterstützung für ein Forschungsinstitut für biologischen Landbau (Fibl) suchte. ${ }^{71}$ Das Fibl in Oberwil (BL) bot eine Antwort auf die Wachstumskritik und den Ruf nach Small is beautiful, welche die verschiedenen politischen Gruppierungen beschäftigte. Der biologische Landbau anerbot sich als positive Aktion, die unterstützt werden konnte. Wenn Vogtman nebenbei in einem Artikel erwähnte, dass der biologische Landbau auch für Entwicklungsländer geeignet sei, zeigt dies die Dominanz der Wachstumskritik, der andere Anliegen jener Zeit unterzuordnen waren. ${ }^{72}$ Es zeigt aber auch, wie sich über die Wachstumskritik und das Motto Small is beautiful neue Allianzen zwischen der Umwelt- und der Dritte-Welt-Bewegung bildeten.

Die noch junge 68er-Bewegung nahm die Umweltfrage sofort auf und setzte sie ebenso rasch als positive Aktion in Form der biologischen Landwirtschaft um. Bereits 1971 betrieben Landkommunen biodynamischen Landbau. ${ }^{73} 1972$ wurde in Basel die landwirtschaftliche Kooperative Longo maï gegründet, die unter anderem im Jura bis heute einen landwirtschaftlichen Betrieb führt. ${ }^{74}$ Ebenfalls entstanden in der Schweiz und in Europa zahlreiche weitere Landkommunen, in welchen oft junge städtische Akademikerinnen und Akademiker die ökologische Selbstbestimmung leben wollten. ${ }^{75}$ Damit haben die Kommunen die Publikation von „Small is Beautiful“ 1973 teilweise vorweggenommen und getragen. Dies wiederum wie bei der Dritte-Welt-Bewegung unter einer neuen Definition des Begriffs Solidarität, nämlich unter dem Motto „Solidarität aller Umweltgeschädigten“. ${ }^{76}$ Erst später, nach dem Erscheinen von „Small is Beautiful“, wurde Schumacher oft als Referenz für bereits Bestehendes angeführt. ${ }^{77}$ Bedeutender als einzelne Kommunen war jedoch die Gründung des Fibl im Jahr 1974. Das Institut

70 P. Kupper: Die ,1970er Diagnose‘, 346.

71 U. Eichenberger: Ökologie und Selbstbestimmung.

72 H. Vogtmann: Der biologische Landbau in der Schweiz. Konzept einer umweltgerechten Alternative, Basler Zeitung, 25.8.1979.

73 S. Bittner: Jenseits der Kleinfamilie, 24.

74 A. Schwab: Landkooperativen Longo maï.

75 U. Eichenberger: Ökologie und Selbstbestimmung, 39.

76 Ebd., 42.

77 Ebd., 43. 
legte Studien zum biologischen Landbau vor und war ein wichtiger Faktor im politischen Prozess, der sich hierzulande in Richtung einer Förderung des biologischen Landbaus entwickelte. Es ist jedoch, wie erwähnt, verfehlt, die Bewegung für Kleinbetriebe und biologische Landwirtschaft als linkes Anliegen oder als Anliegen der 68er-Generation abzutun. Wie aufgezeigt, passte der biologische Landbau auch zum neokonservativen Weltbild. Zudem entsprachen die Wachstumskritik und die Forderung nach der „Rückkehr zum menschlichen Mass“ (Small is beautiful) auch einer grösseren Gruppe von Schweizer (Klein-)Bauern, die mit der offiziellen Landwirtschaftspolitik des Bundes und des Schweizerischen Bauernverbandes nicht einverstanden waren. 1980 spaltete sich in der Schweiz die Kleinbauernvereinigung vom mächtigen Schweizerischen Bauernverband $a b .^{78}$ Die Schweizer Kleinbauern sollten in der Folge im Rahmen von eidgenössischen Abstimmungen immer wieder die Bevölkerung für ihre Anliegen gewinnen können. Ebenfalls wurden die Schweizer Kleinbauern zu einem neuen wichtigen Partner der Umweltbewegung.

Die Fair-Trade-Bewegung wurde zu einer Funktion der Entwicklungen im „Bio“-Bereich. Anne-Marie Holenstein war mit dem Leiter des Fibl, Hardy Vogtmann, per Du, sie wies ihn im Namen der EvB auf „unsere Bemühungen um ökologische Landwirtschaftsmodelle in den Entwicklungsländern“ hin. ${ }^{79} 1981$, als krönender Abschluss der Anstrengungen der 1970er-Jahre, führte das Fibl das Gütesiegel „Die Knospe“ ein. ${ }^{80}$ Schweizer Bäuerinnen und Bauern, die nach den Richtlinien des Fibl anbauten und sich kontrollieren liessen, durften ihre Produkte mit der Knospe versehen. ${ }^{81}$ Damit gab das Fibl eine Strategie vor, die auch im Fair-Trade-Bereich übernommen werden sollte. Etwa gleichzeitig entstanden im Umfeld der EvB Auftragsstudien, die ein ähnliches Gütesiegel für Fair-TradeProdukte prüfen sollten. ${ }^{82}$ Der makroökonomische Sinn eines solchen Gütesiegels wurde in der Bewegung nicht mehr hinterfragt. ${ }^{83}$

Am Goetheanum in Dornach hatte der biologisch-dynamische Landbau bereits zu Beginn des 20. Jahrhunderts eingesetzt. Schon 1928 waren unter der Bezeichnung „demeter“ biologisch-dynamische Produkte erhältlich. ${ }^{84}$ Dann folgte die Konsumenten-Arbeits-Gruppe für tier- und umweltfreundliche Nutztierhal-

78 P. Moser: Schweizerische Vereinigung.

79 SozArch, EvB, Ar 430.91.7. Hardy Vogtmann an Anne-Marie Holenstein, 19. 3.1980. Anne-Marie Holenstein an Hardy Vogtmann, 20.3.1980.

80 D. Ma. [Kürzel]: Mehr Klarheit auf dem Bio-Markt, Basler Zeitung, 11.12.1980.

81 U. Eichenberger: Ökologie und Selbstbestimmung.

82 A.-M. Holenstein-Hasler, R. Renschler, R. H. Strahm: Entwicklung heisst Befreiung, 219.

83 P. Collier: The Bottom Billion, 163.

84 U. Eichenberger: Ökologie und Selbstbestimmung, 56. 
tung (KAG) zu Beginn der 1970er-Jahre mit einem Label. ${ }^{85}$ Wie oben gezeigt, benutzten auch die Frauenfelder Bananenfrauen ein Signet für ihre Bananen, das jedoch bald wieder verschwand. Die Zertifizierung im Bio-Bereich begann bei den Lebensmitteln und führte hier zu den ersten beständigen Gütesiegeln. Die FairTrade-Bewegung hinkte in diesem Bereich stark hinterher. Trotz Bestrebungen in Richtung Gütesiegel ab 1980 sollte in der Schweiz erst zu Beginn der 1990er-Jahre ein Fair-Trade-Label eingeführt werden - und dann auch Bestand haben. ${ }^{86}$

Ebenfalls an der Schwelle von den 1970er- zu den 80er-Jahren folgten verschiedene eidgenössische Volksinitiativen, welche die EvB mitgeprägt oder unterstützt hatte. Diese Initiativen bildeten den Konzeptwandel der Fair-Trade-Bewegung einerseits ab, andererseits zeigen sie auch auf, wie stark die Anliegen der Fair-Trade-Bewegung unterdessen nicht mehr jene einer marginalen Kleingruppierung waren, sondern von einer sehr breiten Bevölkerungsschicht getragen wurden. Mit dem Fokus auf die Bergbauern und die kleinräumige, lokale und bodenständige Produktion überschnitten sich die Anliegen der Dritte-Welt-Bewegung mit jenen eines nationalkonservativ eingestellten oder christlichen $\mathrm{Pu}$ blikums. Die linksgrüne Einstellung, die sich für den Slogan Small is beautiful stark machte, und die nationalkonservative Einstellung - beispielsweise jene des Vorortsdirektors Gerhard Winterberger -, gemäss denen die Schweiz und ihre Bergbauern möglichst erhalten bleiben sollten, erwiesen sich als überraschend deckungsgleich. ${ }^{87}$ Die nationale und kulturelle Identifikation mit dem Bergbauern ist denn auch eine schweizerische Spezialität, die in den Jahren der Geistigen Landesverteidigung stark wurde. ${ }^{88}$ Unter dem Slogan „Schweizerart ist Bauernart“ wurde ein Bild der Schweiz als Nation der hart arbeitenden Bauern und Handwerker kreiert, die der kargen Berglandschaft ihre Früchte abrangen. ${ }^{89}$ Diese Entwicklung zeigte sich etwa darin, dass der Bauernschriftsteller Jeremias Gotthelf während des Zweiten Weltkriegs wiederentdeckt und sein Werk in einer kompletten Ausgabe neu editiert wurde. ${ }^{90}$ Das Interesse an der „bäuerlichen Kultur“ der Schweiz wuchs in der bürgerlichen Gesellschaft in der Kriegszeit und blieb in den Jahrzehnten der Nachkriegszeit eine Konstante. ${ }^{91}$ In den 1970erJahren, als die Dritte-Welt-Bewegung begann, den Kleinbauern als Symbolfigur für ihr Weltbild zu benutzen, hatte sich die bürgerliche Schweiz bereits seit über

85 Siehe die Webseite der KAG, http://www.kagfreiland.ch. (12.9.2017).

86 Das Label Max Havelaar, siehe http://www.maxhavelaar.ch. (12.9.2017).

87 G. Winterberger: Schweizerische Eigenart.

88 J. Solchany: Wilhelm Röpke, 43-45.

89 T. Scheidegger: Vom ,Schweizerbauern'.

90 Gotthelf, Jeremias: Sämtliche Werke in 24 Bänden (Erlenbach-Zürich 1922-1977).

91 J. Solchany: Wilhelm Röpke, 43-45, P. Moser: Stand der Bauern, 61-65. 
drei Jahrzehnten mit der Rolle des Schweizer Bauern im Industriestaat beschäftigt. $^{92}$

Für die Dritte-Welt-Bewegung verkörperte der Kleinbauer eine politische und ökonomische Alternative. Nach der durch den hohen Erdölpreis hervorgerufenen Welternährungskrise von 1973/1974 schien die Ernährungssouveränität und deren Grundlage, das Kleinbauerntum, ein Garant für die Verhinderung weiterer solcher Krisen zu sein, zumal diese Alternative einen Gegensatz zu der von Erdöl abhängigen industrialisierten Landwirtschaft und dem weltweiten Handel von Agrarprodukten darstellte. Die in Kooperativen organisierten Kleinbauern galten sowohl als Gegenstreber rechter Regime, die mit westlichen Multinationalen Firmen unter einer Decke zu stecken schienen, als auch als Träger einer alternativen ökonomischen Praxis. ${ }^{93}$ In Kooperativen organisierte Kleinbauern erschienen der Dritte-Welt-Bewegung als „Dritter Weg“ zwischen Sozialismus und Kapitalismus. ${ }^{94}$

Gleichzeitig lässt sich die Beschäftigung der Dritte-Welt-Bewegung mit der Figur des Kleinbauern in die Missionszeit des 19. Jahrhunderts zurückverfolgen. Es gehörte zur Entwicklungspolitik der Basler Mission, die agrarische, ländliche Entwicklung und die Kleinbauern mit Grundbesitz zu fördern. „Der selbständige Eingeborene auf eigener Scholle“ war für die Basler Mission in Westafrika das erstrebenswerte Gegenstück zum afrikanischen Sklaven oder Plantagenarbeiter. ${ }^{95}$ Die Exportlandwirtschaft wiederum stellte die zivilisierte Alternative zum Handel mit Gold und Sklaven dar. Die Mission förderte das Kleinbauerntum in Afrika aber nicht nur deshalb. Für die pietistisch-protestantischen Basler Stadtbürgerinnen und -bürger sowie die Industriellen entsprach der Kleinbauer auch ihrem romantisch-antiindustriellen Idyll. Das Kleinbauernidyll in Afrika war die Antithese zur industriell-modernen Grossstadt, sei dies nun für Spender in Basel, Genf, London oder in den deutschen Hansestädten. Das Bild des Kleinbauern und Handwerkers im Dorf, von den Basler Missionaren „Salem“ genannt, war eine mehrfache Antithese, zum einen zum Plantagensklaven, zum andern zum städtischen, im Pauperismus gefangenen Industriearbeiter. ${ }^{96}$

Interessant an der Formulierung der Mission ist aber auch die Betonung des Privateigentums. Das Ziel bestand darin, dass der Kleinbauer eigenen Boden besass (bzw. „eigene Scholle“). Dies hatte mit dem biblischen und lutherischen

92 A. Franc: Agricultural Protectionism.

93 Dam, Peter Van: Moralizing Postcolonial Consumer Society, 240.

94 K. J. Kuhn: Fairer Handel und Kalter Krieg, 52.

95 A. Franc: Wie die Schweiz zur Schokolade kam, 241-242.

96 Köppli, Marcel: Protestantische Unternehmer in der Schweiz des 19. Jahrhunderts. Christlicher Patriarchalismus im Zeitalter der Industrialisierung (Zürich 2012). 
Topos des Bauern, der seinen Acker pflügt, weniger zu tun als mit der liberalen Einstellung der Verantwortlichen in Basel, die im Zeitalter des Pauperismus nicht nur Bauern unterstützen, sondern etwa auch Arbeitern zu Wohneigentum verhelfen wollten. ${ }^{97}$ Damit stand das Konzept des Kleinbauern, das die Basler Mission bereits im 19. Jahrhundert hatte, jenem der Hilfe zur Selbsthilfe sehr nahe. Das liberale Konzept der Eigenverantwortung wies damit auch eine enge Nähe zum späteren entwicklungspolitischen Konzept der Hilfe zur Selbsthilfe auf, wie es von der NGO-Bewegung vertreten wurde, die sich jedoch als politisch links verstand.

Es lag somit in diesem gemischt reaktionär-umweltbewussten Geist der Zeit, dass sich gegen Ende der 1970er-Jahre im mächtigen Schweizerischen Bauernverband (SBV) Konflikte um die Agrarpolitik abzeichneten. ${ }^{98}$ Die Kleinbauern erhielten von der nicht agrarischen Bevölkerung der Schweiz Rückendeckung. Die Kleinbauernvereinigung hatte im Gegensatz zum althergebrachte SBV begriffen, dass das Schicksal der „Bauern im Industriestaat“ nicht von deren Produktion, sondern vom Wohlwollen der steuerzahlenden Bevölkerung abhing. Die agrarpolitische Rhetorik der Entwicklungspolitik fokussierte in erster Linie auf die unproduktiven - Bergbauern. ${ }^{99}$ In Zukunft sollte die Schweizer Landwirtschaft nicht in erster Linie die Bevölkerung ernähren, sondern das kulturelle Bedürfnis der Schweizer Bevölkerung nach einer lokalen Landwirtschaft befriedigen. Es ist nicht überraschend, dass die EvB sich mit den Kleinbauern solidarisierte und die Kleinbauerninitiative unterstützte. ${ }^{100}$ Aus der EvB war längst eine Organisation geworden, die sich für biologischen Landbau in der Schweiz, Schweizer Kleinbauern sowie den Tierschutz in der Schweiz einsetzte. Die biologische Produktion in der Schweiz wurde für die EvB zum Primat über den Marktzugang des Südens. So hiess es in ihrem Tätigkeitsbericht über die Jahre 1981 und 1982:

Schon in den Wintermonaten beschäftigen wir uns mit Anbau und Vermarktung von Schweizer Äpfeln. Als Ergänzung zur Aufforderung, keine Früchte aus Südafrika zu kaufen, wurde im Mai ein Faltprospekt herausgegeben ,Ich kaufe...Saisonfrüchte aus der Schweiz، Über dieses Thema werden nun weitere Erfahrungen zum Direktabsatz und zur Deklarationsund Informationspolitik zusammengetragen. Mit den Bananen-Frauen arbeiten wir am Thema ,Äpfel statt Bananen'. ${ }^{101}$

97 Ebd., 156.

98 P. Moser: Schweizerische Vereinigung.

99 W. Baumann, P. Moser: Bauern im Industriestaat, 30.

100 Siehe dazu auf der Webseite der Schweizerischen Bundeskanzlei unter der Rubrik „Volksinitiativen“, Eidgenössische Volksinitiative „für ein naturnahes Bauern - gegen Tierfabriken (Kleinbauern-Initiative)“, (https://www.admin.ch/ch/d//pore/vi/vis167.html) (12.9.2017).

101 SozArch, EvB, Ar 430.16.1. GV 1983, Tätigkeitsbericht 1981/82. 
Auch im Handbuch der EvB zur Aktion „Hunger ist ein Skandal“ von 1981 hiess es, dass „manche lieber Äpfel als Bananen“ essen. ${ }^{102}$ Unmerklich war aus dem Einsatz für einen gerechten Nord-Süd-Handel und für eine Öffnung des Schweizer Marktes für Roh- und potentielle Industrieprodukte des Südens ein Einsatz für die kleinbäuerliche Nahrungsmittelproduktion in der Schweiz geworden. Das Apartheid-Regime in Südafrika bot zunächst ein dankbares Argument für den Kauf von Schweizer Äpfeln, doch auch Bananen aus durchaus demokratisch regierten südlichen Ländern sollten durch Schweizer Äpfel ersetzt werden. Faktisch sollte die Schweiz - im Weltbild der EvB der 1980er-Jahre - als Absatzmarkt für Produkte der Entwicklungsländer wegfallen. So schlich sich denn auch zu Beginn der 1980er-Jahre in Form von Prospekten für die Kleinbauerninitiative unmerklich das Schweizer Kreuz in den Unterlagen des Deutschschweizer Komitees der EvB ein. ${ }^{103}$ Die EvB legte 1984 einem der von ihr verschickten Rundbriefe den Initiativtext der Kleinbauerninitiative und eine positive Stellungnahme bei. ${ }^{104}$

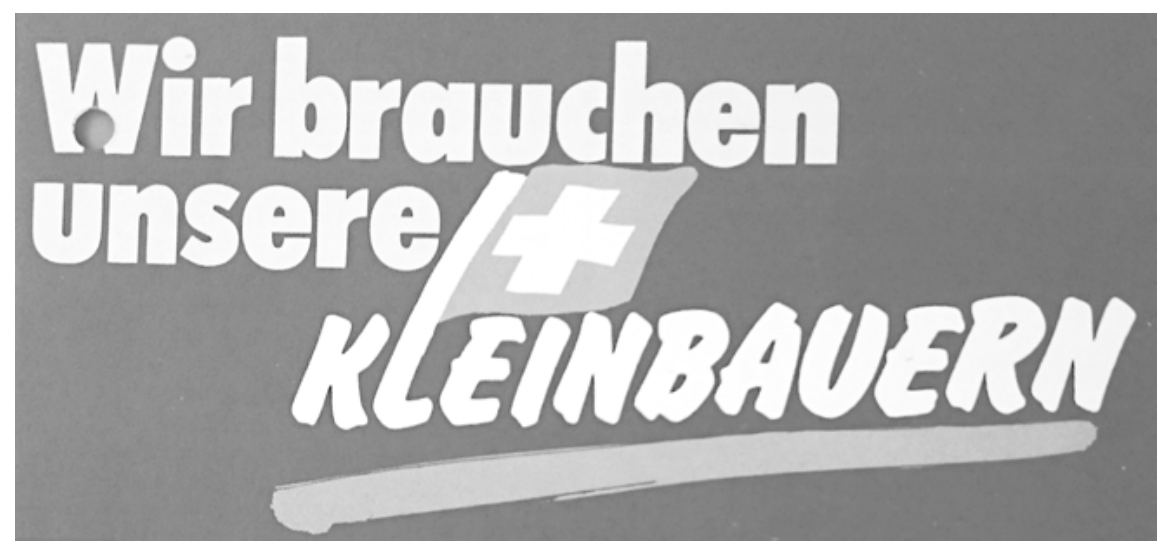

Abb. 9: Informationsbroschüre für die Kleinbauern-Initiative (1984)

Für eine verwandte Initiative, die ein Importverbot von Futtermitteln verlangte, kam der Anstoss von der EvB. ${ }^{105}$ Ausgerechnet im Herbst 1975, in der Phase

102 K. J. Kuhn: Entwicklungspolitische Solidarität, 264.

103 SozArch, EvB, Ar 430.11.5 Informationsbroschüre der Schweizerischen Vereinigung zum Schutz der kleinen und mittleren Bauern für die Kleinbauern-Initiative, 1984.

104 SozArch, EvB, Ar 430.11.5. Protokoll Komiteesitzung vom 13.8.1984, Bern, 13.9.1984.

105 Siehe dazu auf der Webseite der Schweizerischen Bundeskanzlei die Rubrik „Volksinitiativen“, Eidgenössische Volksinitiative „gegen übermässige Futtermittelimporte und Tierfabriken 
des Abstimmungskampfs um das sogenannte Schoggigesetz, einem klassischen neoprotektionistischen Gesetz, das den Import von ausländischen verarbeiteten Nahrungsmitteln wie etwa Schokolade erschweren und für den Export von verarbeiteten Produkten Beiträge vorsehen sollte, entstand der Vorschlag zu einem weiteren, faktisch neoprotektionistischen Gesetz. ${ }^{106}$ Im Protokoll der EvB-Sitzung vom 6. September 1975 wird die anstehende Abstimmung über das Schoggigesetz mit keinem Wort erwähnt. Stattdessen präsentiert Anne-Marie Holenstein einen Vorschlag zur „Eingabe an den Bundesrat betreffend Importbesteuerung von Futtermitteln“. ${ }^{107}$ Das Protokoll hält fest:

Bis November 1975 soll in Zusammenarbeit mit dem i3w ein Dossier zu Frage der Futtergetreideimporte angefertigt werden. Dieses soll als Eingabe an den Bundesrat geschickt werden. Der Text der Eingabe soll dem Komitee vorgelegt werden. Gleichzeitig sollen auch die 2500 Fleischverzichts-Unterschriften mitgeliefert werden. ${ }^{108}$

Es besteht kein Zweifel, dass die EvB eine Abstimmung über ein offensichtlich neoprotektionistisches Gesetz, das Schoggigesetz, das den Anliegen der UjamaaKaffee-Aktion diametral entgegenstand, ignorierte und zur gleichen Zeit aktiv die Arbeit an einem weiteren neoprotektionistischen Gesetz aufnahm. Damit wurden gewisse neoprotektionistische Massnahmen nicht nur passiv geduldet, sondern sogar aktiv gefordert, möglicherweise sogar zeitgleich mit dem ursprünglichen Anliegen, den Markt zu öffnen und die Industrialisierung in den Ländern des Südens voranzutreiben. So standen im von der EvB vertriebenen Buch „Zerstörung durch Überfluss“ (1977) konkrete agrarprotektionistische Forderungen mit dem Ziel der landwirtschaftlichen Autarkie der Schweiz:

\section{Forderungen an die Landwirtschaftspolitik}

Gesetzliche Massnahmen zum Schutz der Bauernbetriebe (z. B. Flächenbeiträge, Verbot der industriellen Tierhaltung, Belastung von Futtermittelimporten) müssen darum vom Konsumenten in seinem eigenen Interessen unterstützt werden. ${ }^{109}$

Unmissverständlich forderte die EvB mit der Herausgabe und Verbreitung dieser Publikation Direktsubventionen („Flächenbeiträge“) an Schweizer Bauern sowie

sowie für bestmögliche Nutzung des einheimischen Bodens“, zurückgezogen für den indirekten Gegenvorschlag am 28.10.1983 (https://www.admin.ch/ch/d/pore/vi/vis130.hl ) (12.9.2017).

106 A. Franc: Wie der Vorort.

107 SozArch, EvB, Ar 430.10.2. EvB Protokoll, 6.9.1975.

108 SozArch, EvB, Ar 430.10.2. EvB Protokoll, 6.9.1975. Das von Komiteemitglied Al Imfeld gegründete und geleitete Informationszentrum Dritte Welt hiess i3w.

109 A.-M. Holenstein, J. Davis: Zerstörung durch Überfluss, 53. 
Importzölle („Belastung“) auf Futtermittel. Die Autorinnen waren sich ebenso unmissverständlich bewusst, dass sie sich damit auf politisch heikles Gebiet wagten: „Viele werden uns vorwerfen, wir geraten mit solchen Überlegungen in die Nähe historisch überholter Vorstellungen von Autarkie."110 Sie konzedierten selbstbewusst, dass sie sich nicht nur in die Nähe, sondern in eine gemeinsame Schnittmenge mit der nationalkonservativen Bewegung der Schweiz begaben:

$\mathrm{Zu}$ welchem dieser beiden grundverschiedenen politischen Standpunkte wir auch persönlich neigen - für einmal treffen sich hier die Vertreter einer solidarischen Weltinnenpolitik mit den Vertretern der isolationistischen Richtung in der Forderung, dass die Schweiz alle Anstrengungen unternehmen muss, um die eigenen Möglichkeiten zur Nahrungsmittelproduktion zu erhalten und zu verbessern. ${ }^{111}$

Dabei appellierten die Autorinnen auch an das Neutralitäts- und Sicherheitsempfinden, das die nationalkonservative Bewegung gerade erst im Bereich der Europa- und Militärpolitik entdeckt hatte:

Wie steht es nun mit der Unabhängigkeit und Selbstbestimmung der Schweiz im Bereich der Ernährung? [...] Merkwürdigerweise besteht keine Forderung, wonach die Schweiz auch in der Lage sein müsste, ihre Neutralität in wirtschaftspolitischen Krisensituationen zu verteidigen. ${ }^{112}$

Den Bemühungen der Autorinnen war Erfolg beschieden. 1978 beschloss schliesslich auch die Generalversammlung der EvB, wie bereits in „Zerstörung durch Überfluss“ gefordert, die Unterstützung der Futtermittelinitiative, die im August des Jahres zustande kommen sollte. ${ }^{113}$ Spannend ist wiederum die Beobachtung, dass die Basis der EvB der eigenen Arbeit kritisch gegenüberstand und noch stärker auf den Kleinbauern fokussieren wollte:

Allerdings sind flankierende Massnahmen notwendig, wenn sie sich nicht letztlich doch wieder zum Nachteil der kleinen Milchbauern auswirken soll. Die Gruppe möchte hierzu Unterlagen erarbeiten, u. a. in direktem Kontakt mit den Kleinbauern. ${ }^{114}$

110 Ebd., 57.

111 Ebd., 58.

112 Ebd., 54.

113 Ebd., 53. Siehe dazu auf der Webseite der Schweizerischen Bundeskanzlei die Rubrik „Volksinitiativen“, Eidgenössische Volksinitiative „gegen übermässige Futtermittelimporte und Tierfabriken sowie für bestmögliche Nutzung des einheimischen Bodens“, zurückgezogen für indirekten Gegenvorschlag am 28.10.1983 (https://www.admin.ch/ch/d/pore/vi/vis130.html) (12.9. 2017). SozArch, EvB, Ar 430.16.1. GV 1978 Auswertung Tagung Gersau.

114 SozArch, EvB, Ar 430.16.1. GV 1978 Auswertung Tagung Gersau. 
Während sich die EvB für den Kleinbauern und den biologischen Landbau in der Schweiz einsetzte, engagierte sich das Fibl wiederum in der Entwicklungspolitik. Über die DEZA war das Forschungsinstitut bereits ab 1979 in ein Projekt in Bolivien involviert. ${ }^{115}$ In seiner Funktion als Experte für biologischen Landbau äusserte sich Hardy Vogtmann, der Leiter des Fibl, wiederum zur Dritten Welt:

Es erscheint auf lange Sicht absurd, ja sogar gefährlich, eine landwirtschaftliche Produktionsmethode zu entwickeln, die extrem abhängig ist von einer grossen Zufuhr an Rohstoffen und Fremdenergie. Dies gilt vor allen Dingen auch im Hinblick auf die Entwicklungsländer. $^{116}$

In diesem Zitat lässt sich die Reduktion der Entwicklungsfrage auf die Landwirtschaft erkennen, die sich gegen Ende der 1970er-Jahre durchsetzte. Waren es in den 1960er- und zu Beginn der 70er-Jahre noch Theologen, Juristen und Ökonomen mit Interesse für Politik, Technik und Handelspolitik gewesen, die sich im Namen der Dritte-Welt-Bewegung geäussert hatten, ging das Expertentum allmählich an die Vertreter der biologischen Landwirtschaft über. Während mehrere asiatische Entwicklungsländer in beträchtlichem Umfang Industrieprodukte in den Westen exportierten und die westlichen Industrieländer Industriearbeitsplätze in asiatische und lateinamerikanische Länder auslagerten, reduzierte sich paradoxerweise das Bild, das die Dritte-Welt-Bewegung von Entwicklungsländern hatte, immer stärker auf die landwirtschaftliche Produktion und auf den Kleinbauern. Während die Landwirtschaft faktisch in zahlreichen Entwicklungsländern an Bedeutung verlor, erfuhr sie in der Beschäftigung der Dritte-Welt-Bewegung eine umso stärkere Aufwertung. ${ }^{117}$ Der Kleinbauer hielt Einzug an so ungewöhnlichen Orten wie etwa dem Fonds zur Unterstützung von Gewerkschaften in der Dritten Welt (Solifonds), zu dessen Arbeitsbereich die „Unterstützung von Bauernbewegungen in ihrem Kampf für Land und Ernährungssouveränität und von Gruppierungen, welche sich für den Schutz der natürlichen Lebensgrundlagen einsetzen“ gehörte. ${ }^{118}$ Das Bild des Kleinbauern hatte in der Weltanschauung der Dritte-Welt-Bewegung über das Bild des Arbeiters gesiegt. Diese Aufwertung der Landwirtschaft und des Kleinbauerntums innerhalb der Dritte-Welt-Bewegung trug zur Ausgestaltung der schweizerischen Agrarpo-

115 U. Eichenberger: Ökologie und Selbstbestimmung.

116 H. Vogtmann: Der biologische Landbau in der Schweiz. Konzept einer umweltgerechten Alternative, Basler Zeitung, 25.8.1979.

117 Dercon, Stefan; Gollin, Douglas: Agriculture in African Development. Theories and Strategies, in: Annual Review of Resource Economics 6/1 (2014) 471-492.

118 S. Howald: Dieses kostbare Gut, 7. 
litik der folgenden Jahrzehnte bei. ${ }^{119}$ Erneut, wie zuvor bei der Aufstockung der öffentlichen Entwicklungshilfe, stand die EvB innert weniger Jahre vor der Situation, dass der Bund ihre Anliegen so rasch und in einem solchen Ausmass umgesetzt hatte, dass sie von der Entwicklung überrumpelt wurde. Die schweizerische Agrarpolitik und die dafür bestimmten Geldsummen wurden in den 1970er- und 80er-Jahren in einem derartigen Tempo ausgebaut bzw. erhöht, dass es für eine kleine NGO nicht mehr möglich war, mit den Entwicklungen Schritt zu halten, jede Abstimmung zum Thema Agrarpolitik intern $\mathrm{zu}$ besprechen und neoprotektionistische Gesetze zu kritisieren.

$\mathrm{Zu}$ gut eignete sich der Kleinbauer als Gallionsfigur und als Marke. Anders als die traditionellen Hilfswerke hatte die EvB nie auf das klassische Marketingbild des hungernden afrikanischen Kindes gesetzt. Mitte der 1970er-Jahre wird der Kleinbauer jedoch zunehmend zum Markenzeichen in Texten aus der Feder der EvB-Sekretäre. ${ }^{120}$ Die EvB nahm damit eine Entwicklung vorweg, die auch die klassischen Hilfswerke mitmachen sollten: Die Abkehr von der Hilfe als Almosen und die Hinwendung zur Hilfe zur Selbsthilfe. Dies bedeutete: weg vom Bild des hungrigen Kindes, hin zum Bild des Kleinbauern. ${ }^{121}$ Die Marketing- und Fundraisingstrategien der Hilfswerke wurden für den Fall Grossbritanniens gleich mehrfach untersucht. ${ }^{122}$ Die britische Oxfam steuerte den Übergang vom Bild des hungernden afrikanischen Kindes zum Bild des Kleinbauern bereits in den 1960er-Jahren an. Oxfam war zu dieser Zeit bereits eine hochprofessionelle NGO mit einem ebenso professionellen Fundraising und Marketing. Bereits mit dem Bild des afrikanischen Kindes, das damals neu war bzw. die Bilder der europäischen Flüchtlingskinder nach dem Zweiten Weltkrieg ersetzte, hatte Oxfam einen Marketingerfolg gelandet. ${ }^{123}$ Für die westliche Konsumgesellschaft der 1960erJahre waren die Fotos der hungrigen Kinder schockierend. Wie stark es bei diesem Wechsel auch um Fundraising, Marketing und die Konkurrenz unter den verschiedenen Hilfswerken um nationale Aufmerksamkeit und somit Spenden ging, zeigt wiederum Black:

Press advertising became more hard-hitting. This was the heyday of the hungry child. [...] Oxfam was part of a new consciousness about the world. Just as the image of the starving

119 P. Moser: Stand der Bauern, 311-312.

120 Siehe dazu etwa A.-M. Holenstein, J. Davis: Zerstörung durch Überfluss oder A. Bänziger: Entwicklungsland Welt - Entwicklungsland Schweiz.

121 M. Black: Oxfam the First 50 Years, 69.

122 M. Hilton: Politics of Expertise. Eine Ausnahme findet sich bei K. J. Kuhn: Entwicklungspolitische Solidarität, 229.

123 L. Zürcher: ,Das Brot des Lebens‘, 52. 
child of the Congo was new, so too was the image of the 'progressive farmer' leaving hunger behind on the basis of a sum well within the reach of anyone's comprehension. ${ }^{124}$

Der Kleinbauer war, wie Black bemerkt, eine für jeden westlichen Bürger einfach greifbare Figur. Und: Das Bild des Kleinbauern wurde, wie bereits jenes des hungernden afrikanischen Kindes, in einem immer aggressiver werdenden Werbeumfeld genutzt. Mit der Figur des Kleinbauern war nun auch die EvB auf dem Boden der Realität angekommen, der sich die professionellen NGOs im Bereich Marketing und Fundraising europaweit stellen mussten. Die reine Entwicklungshilfe - versinnbildlicht durch das hungernde Kind - hatte sie noch kritisiert und als zu simpel verworfen. Nun, in der zweiten Phase, gekennzeichnet durch eine erweiterte Neudefinition der Entwicklungshilfe, die sich in den 1970er-Jahren unter den NGOs durchsetzen sollte, war die EvB an vorderster Front mit dabei. Sie hatte sich, ohne dies zu reflektieren, in einen bereits fahrenden, internationalen Zug gesetzt: Seit den 1980er-Jahren waren „Hungerbilder“ generell in Werbekampagnen von Entwicklungsorganisationen im Rückzug. ${ }^{125}$ Die Neudefinition der Entwicklungshilfe als Selbsthilfe, als Entwicklungszusammenarbeit, setzte keine Hungersnot, keinen Krieg oder sonstige akuten Ereignisse voraus. Die Entwicklungszusammenarbeit war im Gegensatz zur Entwicklungshilfe ein kontinuierlicher, langfristiger Prozess. Sie war eine Grundlagenarbeit, die in jedem Entwicklungsland und jederzeit erfolgen konnte. Da sie kein Ereignis voraussetzte, war sie planbar. Für die Hilfswerke genau wie für die staatlichen Entwicklungsministerien war der Übergang von der Entwicklungshilfe zur Entwicklungszusammenarbeit die Bedingung ihres Organisationswachstums. Das Bild des Kleinbauern versinnbildlicht die Professionalisierung der Entwicklungszusammenarbeit in der westlichen Welt und ein Geschäftsmodell, das zumindest im Westen zahlreiche Arbeitsplätze geschaffen und erhalten hat. ${ }^{126}$ Während sich die EvB in ihrem Selbstbild als eine vom Staat unabhängige Instanz sah, deren Aufgabe darin bestand, die schweizerische Entwicklungszusammenarbeit kritisch zu begleiten, sind die parallel verlaufenden Entwicklungen ihrer Konzeptänderung und der Aufbau der DEZA ${ }^{127}$ sowie die wiederkehrende Zusammenarbeit mit der späteren DEZA unübersehbar. Sie reihen sich ein in die für Grossbritannien beobachtete Forschung, die den Aufbau professioneller NGOs als komplementär zum Ausbau staatlicher Leistungen sieht. ${ }^{128}$ Bereits im September 1972 wird Anne-

124 M. Black: Oxfam the First 50 Years, 80.

125 C. Gerlach: Bilder des Hungers, 29.

126 Siehe dazu etwa W. R. Easterly: The White Man oder R. Vaubel: Bureaucracy at the IMF.

127 D. Waldburger, L. Zürcher, U. Scheidegger: Im Dienst der Menschheit.

128 M. Hilton: Politics of Expertise. 
Marie Holenstein dem Bundesrat zur Wahl in die Kommission für technische Zusammenarbeit vorgeschlagen. ${ }^{129}$ Daraufhin wurde die EvB etwa 1973 in das Vernehmlassungsverfahren zum Zuckerbeschluss oder 1974 in jenes zum Bundesgesetz über die internationale Entwicklungszusammenarbeit und humanitäre Hilfe eingebunden. ${ }^{130}$ Dieses Gesetz von 1976, auf dem der Ausbau der DEZA in den folgenden Jahrzehnten beruhte, hat die EvB stark mitgeprägt. ${ }^{131}$ Zum anderen haben ihre Vertreterinnen und Vertreter Kurse veranstaltet für DEZA-Mitarbeiterinnen und Mitarbeiter und sich mit diesen auch eingehend unterhalten. ${ }^{132}$ So berichtet etwa Strahm 1976 beiläufig in einer Notiz an seinen Kollegen vom Westschweizer EvB-Komitee: „Ich hatte diese Woche ein vierstündiges Gespräch mit zehn Mitarbeitern des Dienstes für Technische Zusammenarbeit über mein Finanzhilfe-Papier." ${ }^{133}$ Ende der 1970er-Jahre bestand ein impliziter Konsens, wonach der Kleinbauer die gemeinsame Schnittmenge von Politik und öffentlicher Entwicklungszusammenarbeit war. Dieser Konsens wurde auch von der EvB getragen.

\subsection{Das Ende der Modernisierung: Allianz mit den Gewerkschaften, gegen Staudämme}

In der „Erklärung von Bern“ hatte es 1968 geheissen, dass sich die Schweizer Bevölkerung darauf einstellen müsse, auf „Privilegien zu verzichten“. ${ }^{134}$ Im Sinne der UNCTAD-Doktrin, auf die sich die Erklärung bezieht, bedeutete dies, in eine faire Konkurrenz zu den Ländern des Südens zu treten und auf den Schutz der Binnenwirtschaft durch Einfuhrzölle und andere protektionistische Instrumente zu verzichten. „Privilegien aufgeben“ hiess - implizit auf die spätere PulverkaffeeAktion angewendet -, dass die Schweizer Bevölkerung sich darauf einstellen sollte, dass ihr Pulverkaffee in Zukunft nicht aus einer Nestlé-Fabrik in Vevey,

129 SozArch, EvB, Ar 430.10.1. Schweizer Komitee 1970 - 1973, Stellvertreter des Delegierten für technische Zusammenarbeit, Eidgenössisches Politisches Departement, an Anne-Marie Holenstein, 8.9.1972.

130 SozArch, EvB, Ar 430.10.1. Schweizer Komitee 1970 - 1973, Anne-Marie Holenstein, Georges Rossier an Eidgenössisches Volkswirtschaftsdepartement, 4.10.1973.

131 R. Spörri: Einfluss der Erklärung von Bern.

132 A.-M. Holenstein-Hasler, R. Renschler, R. H. Strahm: Entwicklung heisst Befreiung, 235.

133 SozArch, EvB, Ar 430.12.1. Comité romand : Rudolf Strahm an François [de Vargas] und Mario [Carera], 21.12.1976.

134 Punkt 5, Die Erklärung von Bern, https://www.publiceye.ch/fileadmin/files/documents/Ue ber_uns/EvB_1968_0.pdf (28.3.2018). Siehe auch SozArch, EvB, Ar 430.25.1. EvB, Anfangszeit: Die Erklärung von Bern, März 1968. 
sondern aus einem Staatsbetrieb in Tansania kommen würde, und dass auch die Dividenden und Steuereinnahmen für eine solche Produktion nicht mehr in der Schweiz, sondern in einem Land des Südens anfallen würden. Diese Erkenntnis, dass auch Arbeiter um ihre Arbeitsplätze konkurrierten, wurde bereits in Punkt 5 der Erklärung angesprochen und war daraufhin immer wieder ein Thema in internen Papieren. Trotzdem ging diese Erkenntnis auf dem kommenden Weg, den die Bewegung ging, verloren. Die ökonomisch korrekte Beobachtung der kurzfristigen Wirkung offener Märkte wurde ersetzt durch ein widersprüchliches, falsch verstandenes sozialistisches Verständnis von Solidarität unter Arbeitern oder Bauern. Die in den 1970er-Jahren stärker werdende Kritik an multinationalen Konzernen und an der Weltbank brachte auch eine neue Konzentration auf Kleinbauern und Arbeiter mit sich. Wie erwähnt, unterschied die Bewegung auch stärker zwischen der einheimischen Elite und der Unterschicht, dies als Folge der Militärcoups und Korruptionsskandale in vielen gerade eben unabhängig gewordenen Entwicklungsländern. ${ }^{135}$ Während eine Solidarität zwischen Kleinbauern in Nord und Süd suggeriert wurde, der jedoch faktisch die Unterstützung der Agrarwirtschaft in Milliardenhöhe im Wege stand, wurde auch eine Solidarität zwischen Arbeitern heraufbeschworen, der ebenfalls ab Mitte der 1970er-Jahre ein neu erwachter und neuartiger nationaler oder europäischer Protektionismus im Wege stand. ${ }^{136}$ Ähnlich einem Think-Tank, definitiv dem akademisch-ökonomischen Einwand entzogen, definierte die Dritte-Welt-Bewegung nicht nur den Agrar-, sondern auch den Industrieprotektionismus neu: Nationaler Protektionismus war nun nicht mehr ein Privileg wohlhabender Westler, sondern legitimer Schutz einer globalen Arbeiterschaft - der ,vom Wachstum überfahrenen urbanen Massen“. ${ }^{137}$ Nach einer kurzen, von der UNCTAD von 1964 eingeflüsterten ökonomischen Pause wurde der alte sozialistische Slogan „Arbeiter aller Länder vereinigt Euch“ wieder aktuell - wenn auch in neuer, ökonomisch inkorrekter Form.

Ende der 1970er-Jahre stiessen die Gewerkschaften zur Dritte-Welt-Bewegung hinzu. Die Widersprüchlichkeit, die im neuen Konzept zum gerechten Handel steckte, wurde damit verfestigt. Im gleichen Zug zementierten die Gewerkschaftsführer jedoch den Verlust ihrer Basis. Während sich die Gewerkschaftsspitzen gemeinsam mit dem erstarkenden NGO-Sektor für Dritte-Welt-Anliegen einzusetzen begannen, trug die Basis dies nicht mit: „Unsere Leute [...] empfinden

135 R. Gildea, J. Mark, A. Warring: Europe's 1968, 193.

136 SozArch, EvB, Ar 430.17.6. Handakten Regula Renschler: Kinder und Dritte Welt (II), Ar 430.91.2. Handakten Regula Renschler: Nachlieferung 2009, Teil 2. Lehrerfortbildung/Kurse Kanton Bern, Lektionenreihe „Drei Dörfer“, 1975-1978. J. N. Bhagwati: Protectionism, 1.

137 R. H. Strahm: Beziehungen Schweiz Dritte Welt. 
die Dritte-Welt-Länder und ihre Arbeitskräfte als Konkurrenz und Bedrohung des eigenen Arbeitsplatzes“, erklärte etwa ein Gewerkschaftssekretär 1981 im Rahmen der Gründung des Solifonds gegenüber den Medien. ${ }^{138}$ Die Basis durchschaute die Widersprüchlichkeit der vermeintlichen Solidarität.

Die stets fragile Zusammenarbeit zwischen der Dritte-Welt-Bewegung und den Gewerkschaften muss auf zwei Ebenen betrachtet werden. Zum einen auf jener der wirtschaftlichen Konjunktur, zum anderen auf der diskursiven Ebene, die Widersprüche übertünchte und so politische Allianzen zwischen Dritte-WeltNGOs und den Gewerkschaften möglich machte. Als die Verfasser der „Erklärung von Bern“ 1968 an die Schweizer Öffentlichkeit traten, herrschte überhitzte Hochkonjunktur auf dem Arbeitsmarkt, die Gewerkschaften waren auf dem Höhepunkt ihres politischen Einflusses und verfügten über politische Verhandlungsmacht, da Arbeitskräfte knapp waren. ${ }^{139}$ Als die erste Generation der EvB verkündete, die Schweiz müsse in Zukunft Privilegien aufgeben, schien dies für die Gewerkschaften nicht sonderlich bedrohlich zu sein. Nach der Wirtschaftskrise von 1973 und mit der zunehmenden Auslagerung von Schweizer Industriearbeitsplätzen ins Ausland änderten sich jedoch die Vorzeichen für die Gewerkschaften. Der Erhalt und die Schaffung von Arbeitsplätzen im Industriesektor wurden bei jeder politischen Vorlage, welche die EvB bekämpfte, zur Klippe, die sie mit den Gewerkschaften im Schlepptau diskursiv umschiffen musste. So formulierte die EvB in einem internen Positionspaper ihr politisches Hauptziel zu Beginn der 1980er-Jahre wie folgt: „Versuchen, mit den Gewerkschaften ins Gespräch zu kommen: Ziel: Verhindern, dass entwicklungspolitische und gewerkschaftliche Kreise einander entgegenwirken. “140

In den 1970er-Jahren fand in der Schweiz ein tiefgreifender wirtschaftlicher Umbruch statt. Während der Industriesektor zahlreiche Arbeitsplätze abbaute oder nicht selten in Entwicklungsländer verlagerte, erstarkte der Dienstleistungssektor. ${ }^{141}$ Für die traditionell im Industriesektor verhafteten Gewerkschaften bedeutete dieser wirtschaftliche Strukturwandel jedoch ein Schwinden ihres Wirkungsbereichs. ${ }^{142}$ Die Kritik an den multinationalen Konzernen, die ihre Arbeitsplätze auslagerten, und an den Bretton-Woods-Institutionen, die solche

138 K. B., Produktionsverlagerung ins Ausland: Konkurrenzangst gegen Solidarität, Basler Zeitung, 2.6.1981.

139 Halbeisen, Patrick et al.: Wirtschaftsgeschichte der Schweiz im 20. Jahrhundert (Basel 2012) $910-911$.

140 SozArch, EvB, Ar 430.11.5. Entwurf für die Weiterarbeit im Bereich der Wirtschaftspolitik, Termin: Mai - bis Ende 1984.

141 Halbeisen, Patrick et al.: Wirtschaftsgeschichte der Schweiz im 20. Jahrhundert, 123.

142 Ebd., 910-911. 
privaten Auslanddirektinvestitionen förderten, war somit für die Gewerkschaften naheliegend. Ebenfalls naheliegend war eine Affinität zur marxistisch-leninistischen Haltung, wonach Privatinvestitionen in Ländern des Südens abgelehnt wurden. 1978 erstellte Rudolf Strahm eine Projektskizze für einen „Kampffonds für die Arbeiter in der Dritten Welt“, der die „Abbkopplungsthese“ zugrunde lag. Die bisherige Entwicklungszusammenarbeit des Bundes bezeichnete Strahm darin als „Rekolonisationsvorgang“. ${ }^{143}$ Die Skizze sah eine Solidarität zwischen Peripherie und Peripherie vor, das heisst zwischen den verbliebenen oder entlassenen Industriearbeitern in der Schweiz und der neuen Schicht der Industriearbeiter in den Entwicklungsländern. Der „Kampffonds“ sollte eine Gegenmacht zu den schweizerischen Konzernen in den Entwicklungsländern aufbauen und nach dem Konzept der self-reliance (der Abkopplung) den Aufbau einer heimischen Industrie aus eigenen nationalen Ressourcen fördern. Konkret sollte er Streiks in Fabriken von Schweizer Konzernen in Entwicklungsländern unterstützen. Im Arbeitsprogramm des Schweizerischen Gewerkschaftsbundes stand zwar offiziell, dass dieser eine solidarische Wirtschaftsordnung auch mit Einbussen für die Industrieländer anstrebe. Faktisch verlockte jedoch die Idee, ein Instrument zu schaffen, das eine Opposition zur bürgerlichen Aussenwirtschaftspolitik des Bundes darstellte, und somit der Privatwirtschaft mit ihren Auslanddirektinvestitionen den Kampf anzusagen. Der von Strahm skizzierte Kampffonds sollte 1983 als Stiftung unter dem Namen Solifonds entstehen, mit einem als Konzession an die Machbarkeit allerdings offen formulierten Stiftungszweck, der Streiks in Schweizer Filialen nicht direkt benannte. ${ }^{144}$

Die Gründung des Solifonds besiegelte somit die ablehnende Haltung gegenüber den privaten Auslanddirektinvestitionen im Süden in einem sehr breiten linken, sozialdemokratischen und christlich-tiermondistischen Lager. Während Ende der 1970er-Jahre noch als Gegenkonzept die Abkopplung vorgebracht wurde, verschwand in den 1980er-Jahren überhaupt der Anspruch auf Modernisierung in der Dritten Welt. Diese Ablehnung nahm den Umweg über die aus politischen Gründen geäusserte Kritik an Modernisierungsprojekten. Auftakt war die im Rahmen der Anti-Apartheid-Bewegung europaweit geäusserte Kritik an den südafrikanischen, rhodesischen und portugiesischen Regierungen und deren Investitionen sowie an Aufträgen an multinationale Firmen. ${ }^{145}$ Bereits 1970 formierte die EvB in der Schweiz erstmals Widerstand gegen ein grosses Staudammprojekt. Es ging um den Cabora Bassa Damm in Mosambik. Das Land war

143 B. Graf: Gewerkschaften und Dritte Welt.

144 S. Howald: Dieses kostbare Gut.

145 The Cabora Bassa Dam [Titel der Ausgabe], The Internationalist, Nr. 2, Januar bis Mai 1971. 
damals noch eine portugiesische Kolonie und grenzte an das Apartheid-Regime Südafrikas. Die EvB-Komitee-Mitglieder André Biéler, Lukas Vischer und insbesondere Pierre Bungener, Direktor des Institut africain in Genf, erarbeiteten eine öffentliche Stellungnahme der EvB gegen die Schweizer Beteiligung am Staudamm. ${ }^{146}$ Dass Jean Ziegler 1970 als SP-Nationalrat in einer seltenen Zusammenarbeit mit der EvB eine Anfrage an den Bundesrat zum Cabora Bassa Damm richtete, markierte zudem die politische Note dieser Angelegenheit. ${ }^{147}$

Anfang der 1980er-Jahre wählte die EvB die Verhinderung des Baus von Wasserkraftwerken durch Schweizer Industrieunternehmen offiziell zum Thema ihres Pfeilers Wirtschaftspolitik. „Projektgigantismus“ und „Mammutprojekte“ seien eine „Fehlentwicklung“, die „,auf den Schultern der ärmsten Bevölkerung“ laste, hiess es in einem internen Papier. Wiederum zeigt sich hier die implizite Überschneidung mit dem Neokonservatismus röpkescher Prägung; man erinnere sich: Röpke verabscheute „Industrie-Giganten“. ${ }^{148}$ Mit „Öffentlichkeitsarbeit, Lobbying, Information, mehr Tagespolitik auf institutioneller Ebene“ wollte die EvB in den 1980er-Jahren die Beteiligung von Schweizer Firmen an Kraftwerkprojekten in der Dritten Welt verhindern. Die Gründe für die Kritik an Staudämmen verschoben sich. ${ }^{149}$ Der Staudamm sollte in den 1980er-Jahren zum Symbolbild der industriebasierten Modernisierung werden, sozusagen ein Gegenbild des Handarbeit leistenden Kleinbauern auf dem Land. Wiederum fügte sich die EvB hier in eine internationale Bewegung und Entwicklung ein, die 1985 in der Gründung einer internationalen NGO zur Verhinderung von Staudammprojekten mündete. ${ }^{150}$ Erneut wird hier eine Kontinuität sichtbar: Im 19. Jahrhundert war die Verwirklichung eines Gegenbildes zur Industriestadt Basel in den ländlichen südlichen Missionsfeldern ein wichtiger Antrieb der Basler Mission. ${ }^{151}$ Die Vehemenz, mit der die EvB gerade Staudämme herausgriff und ihr ideales Bild des Südens daran mass, wird nicht nur vor dem Schweizer Hintergrund augenfällig, wo Staudämme und Wasserkraftwerke einen bedeutenden Anteil an der Elektri-

146 A.-M. Holenstein-Hasler, R. Renschler, R. H. Strahm: Entwicklung heisst Befreiung, 51. SozArch, EvB, Ar 430.25.3. Mappe 4: Cabora Bassa-Staudamm 1970, Stellungnahme EvB.

147 A.-M. Holenstein-Hasler, R. Renschler, R. H. Strahm: Entwicklung heisst Befreiung, 50.

148 SozArch, EvB, Ar 430.11.5. Entwurf für die Weiterarbeit im Bereich der Wirtschaftspolitik, Termin: Mai -bis Ende 1984. Röpke, Wilhelm: Die Schweiz im Strome der Weltwirtschaft, in: Schweizer Monatshefte 39/6 (1960) 477-488.

149 SozArch, EvB, Ar 430.11.5. Entwurf für die Weiterarbeit im Bereich der Wirtschaftspolitik, Termin: Mai -bis Ende 1984. Siehe dazu das Konvolut „Kraftwerke“ in: SozArch, EvB, Ar 430.63.1. Kraftwerke/Staudämme 1984-1986. Sowie Ar 430.63.2. Ludwig-Institut/Jari-Projekt in Brasilien $1979-1982$.

150 Die NGO International Rivers, siehe http://www.internationalrivers.org (13.9.2017).

151 A. Franc: Wie die Schweiz zur Schokolade kam, 241-242. 
fizierung des Landes und der darauffolgenden Industrialisierung und Wohlstandssteigerung leisteten. Die EvB hat auch, wie die neuere Forschung aufzeigt, die Bedeutung von Staudämmen als Symbol der Modernisierung für Länder des Südens nicht Ernst genug genommen. ${ }^{152}$

Doch die Diskussion um Staudämme verhindert den Blick auf die eigentliche Neuausrichtung, welche die wirtschaftspolitische Haltung der EvB zu Beginn der 1980er-Jahre vornahm. Sie war fundamental, aber dennoch subtil, und muss deshalb an dieser Stelle genauer ausgeführt werden. Wie erwähnt ging ein Konzeptwandel vonstatten, der sich an den Fair-Trade-Produkten ablesen lässt: Während in einer ersten Aktion industriell hergestellter Pulverkaffee aus Tansania verkauft wurde, waren es später in Handarbeit gefertigte Jutetaschen und schliesslich die klassischen tropisch-kolonialen Agrarrohstoffe Kaffeebohnen, Bananen und Tee. Die EvB als NGO hatte den Verkauf von Produkten allerdings 1977 outgesourct und konzentrierte sich nun auf eine andere, wirtschaftspolitische Ebene. Sie war zu einem intellektuellen Think-Tank geworden und produzierte ein paraakademisches Weltbild, das die Entwicklung im outgesourcten Produktebereich konzeptuell begleitete. Bei der Betrachtung der Entwicklung der wirtschaftspolitischen Haltung der EvB wird offensichtlich, dass sich ihr Bild der Entwicklungsländer als Rohstofflieferanten verändert hatte. Bereits 1968 waren die Initianten der Erklärung davon ausgegangen, dass Entwicklungsländer faktisch Rohstofflieferanten waren. Sie zogen aus dieser Tatsache jedoch andere Schlüsse als das Personal der unterdessen professionalisierten NGO zu Beginn der 1980er-Jahre. Diese Reaktion auf die Rolle der Entwicklungsländer als Rohstofflieferanten und die entsprechenden Schlussfolgerungen machen den Unterschied bzw. den Konzeptwandel der Bewegung zwischen 1964 und 1984 aus. Die Initianten von 1968 gingen davon aus, dass die Entwicklungsländer dem Fallstrick der Rohstoffproduktion, der zu einer zunehmenden Verschlechterung ihrer realen Austauschverhältnisse und somit zu einer Öffnung der Schere zwischen Nord und Süd führen würde, entkommen müssten. Sie hingen der Utopie an, dass die Entwicklungsländer schon bald eine verarbeitende Industrie aufbauen und die Wertschöpfungskette ins Land holen würden. So forderten sie die Schweizer Industriekonzerne auf, dieser Entwicklung nicht im Wege zu stehen, sondern ihr im Gegenteil Vorschub zu leisten und in verarbeitende Industriebetriebe vor Ort $\mathrm{zu}$ investieren.

1984 war die Haltung des EvB-Teams eine andere: Für die Angestellten der NGOs war der Rohstoffkauf von Schweizer Konzernen in der Dritten Welt eine

152 Miescher, Stephan F.: Building the City of the Future. Visions and Experiences of Modernity in Ghana's Akosombo Township, in: The Journal of African History 53/3 (2012) 367-390. 
statische Tatsache, die sich nicht verändern liess. Die Vorstellung, dass sich an dieser Situation in Zukunft etwas ändern könnte, sowie die Vorstellung, dass sich an dieser Situation etwas ändern sollte und eine industrielastige Modernisierung stattfinden müsse, war verschwunden. Zu Beginn der 1980er-Jahre beschränkte sich die EvB darauf, über die Schweizer Konzerne $\mathrm{zu}$ „recherchieren“ und die Situation, von der sie nun annahm, dass sie statisch-unveränderlich war, kritisch zu begleiten. Die Situation der Entwicklungsländer als Rohstofflieferanten sollte nicht grundlegend geändert, sondern einzig verbessert werden. Dies war die subtile, aber fundamentale Konzeptänderung. 1983, als das EvB-Team intern besprach, welche wirtschaftspolitischen Schwerpunkte zu setzen seien, hegte es für das kommende Jahr 1984 die folgenden Pläne:

Projektarbeit 1984:

Information: RB [Rundbrief] Beilage Nr. 1 über Handel. Versuch, UTC und Volkart unter die Lupe zu nehmen. Thema Rohstoffe. ${ }^{153}$

Wie einfallslos, müde und wissenschaftlich schwach war die EvB in diesem Schicksalsjahr 1983 geworden! Einzig das Abspulen der altbekannten Leier kam ihr in den Sinn. Die beiden bekannten Schweizer Kolonialhandelsgesellschaften UTC und Volkart waren ein Jahrhundert nach ihrer Gründung, während des goldenen Zeitalters der Globalisierung in den 1950er-und 60er-Jahren, noch einmal zu einer kurzen wirtschaftlichen Blüte gekommen. ${ }^{154}$ Doch bereits in den 1970erJahren hätten aufmerksame Beobachter erkannt, dass die Tage der klassischen Kolonialhandelsgesellschaften gezählt waren, und Mitte der 1980er-Jahre war das Schicksal der beiden Gesellschaften, die beide in den 1990er-Jahren faktisch aufgelöst wurden, besiegelt. Das müde Team der EvB fiel auch symbolisch in die Kolonialzeit zurück. Rohstoffe und Schweizer Kolonialhandelsgesellschaften: So sah die Vorstellung der EvB aus, die ihre Arbeit mit den Entwicklungsländern damals charakterisierte. Dabei hätte ein wacher und wissenschaftlich geschulter Blick erkannt, dass gerade der Niedergang und Rückzug westlicher Firmen insbesondere in Afrika - die 1980er-Jahre prägte, was sogar auf jene Unternehmen zutraf, die seit Jahrzehnten Handel trieben mit dem Süden und viel Kapital im

153 SozArch, EvB, Ar 430.11.5. Entwurf für die Weiterarbeit im Bereich der Wirtschaftspolitik, Termin: Mai - bis Ende 1984.

154 Dejung, Christof: Die Fäden des globalen Marktes. Eine Sozial- und Kulturgeschichte des Welthandels am Beispiel der Handelsfirma Gebrüder Volkart 1851-1999 (Köln 2013), A. Franc: Wie die Schweiz zur Schokolade kam. 
Rücken hatten. ${ }^{155}$ Der sogenannte Washington consensus war denn auch eine Antwort auf die in den 1980er-Jahren ausbleibenden Investitionen in verarbeitende Betriebe in Staaten Lateinamerikas und insbesondere Afrikas. ${ }^{156}$ Anstatt diesen Rückzug der westlichen Konzerne aus Entwicklungsländern zu erkennen, zu kommentieren und eine entwicklungspolitische Haltung der Schweiz dazu zu entwerfen, fiel die EvB in koloniale Muster zurück: die Kritik an den wenigen bekannten, sichtbaren und überhaupt noch verbleibenden Firmen im Süden und an deren Rohstoffhandel.

\subsection{Parlamentarier im Dienste der Erklärung von Bern}

Es ist auffällig, wie unpolitisch die Erstunterzeichner der „Erklärung von Bern“ waren. Wie schon erwähnt, trat 1968 die Kirche, bzw. ihre Vertreter wie Pfarrer und Theologieprofessoren, noch als eigene Kraft im Staat auf. Die Verflechtung der Dritte-Welt-Bewegung mit der nationalen Politik kam erst später und spiegelt eine langsame „Entkirchlichung“ und ein Einfliessen des ursprünglich kirchlich gebundenen Dritte-Welt-Engagements in die Politik wider. ${ }^{157}$ Manche Namen, die in den frühen Akten der EvB auftauchen, sollten erst in den 1980er- oder sogar 90erJahren auf nationaler Ebene politisch bekannt werden. So engagierte sich etwa die Juristin Lilian Uchtenhagen im Frühling 1969 für die Bekanntmachung der „Erklärung von Bern“. ${ }^{158}$ Erst ein Jahr später sollte sie für die SP in den Gemeinderat der Stadt Zürich gewählt werden, 1983 sollte ihre Nichtwahl in den Bundesrat für Aufsehen sorgen. ${ }^{159}$ Uchtenhagen gehörte auch dem Vorstand der OS3 an. ${ }^{160}$ Ähnliches gilt für den Zürcher Rechtsanwalt Moritz Leuenberger, der die EvB rechtlich vertrat, lange bevor er 1995 in den Bundesrat gewählt wurde. ${ }^{161}$

155 J. Toye, R. Toye: UN and Global Political Economy, 257, N. Stettler: Basler Handelsgesellschaft.

156 J. Toye, R. Toye: UN and Global Political Economy, 260.

157 U. Hofmann: Innenansichten eines Niedergangs, 262.

158 A.-M. Holenstein-Hasler, R. Renschler, R. H. Strahm: Entwicklung heisst Befreiung, 142.

159 Baertschi, Christian: Uchtenhagen, Lilian, in: Marco Jorio (Hg.): Historisches Lexikon der Schweiz (Basel 2002-2014) http://www.hls-dhs-dss.ch/textes/d/D3318.php (19.9.2016).

160 Siehe den Eintrag der Claro Fair Trade AG im Handelsregister des Kantons Bern auf http:// www.zefix.ch.

161 SozArch, EvB, Ar 430.11.5 Einschreiben des Advokaturbüros Leuenberger Meier Gsell Mona an das Verwaltungsgericht des Kantons Zürich, 19.10.1983. Siehe auch M. Kalt: Tiersmondismus in der Schweiz, 423-427. Bürgi, Markus: Leuenberger, Moritz, in: Marco Jorio (Hg.): Historisches Lexikon der Schweiz (Basel 2002-2014) http://www.hls-dhs-dss.ch/textes/d/D33679.php (16.1. 2008). 
Derweil wurde der frühere Sekretär des Westschweizer Komitees der EvB, Mario Carera, Leuenbergers persönlicher Mitarbeiter. ${ }^{162}$ Noch stärker gilt diese Beobachtung für Ruth Dreifuss, die 1980 als einfaches SP-Mitglied und Mitarbeiterin der DEZA-Vorgängerorganisation Rudolf Strahm bei der Gründung des Solifonds unterstützte. ${ }^{163}$ Die Verankerung Dreifuss' nicht nur in der Gewerkschaftsbewegung, sondern auch in der sehr breiten bürgerlich-christlichen Dritte-Welt-Bewegung liefert ein weiteres erklärendes Puzzleteil für ihre plötzliche Wahl in den Bundesrat 1993. Auch Rudolf Strahm, der die EvB so gewichtig geprägt hatte, sollte erst nach seinem Weggang von der EvB der SP beitreten und 1991 in den Nationalrat gewählt werden. ${ }^{164}$ So ist denn auch auffällig, dass die Bewegung im Umkreis der EvB in den Anfangsjahren kaum mit dem 1967 für die SP in den Nationalrat gewählten Afrikaspezialisten Jean Ziegler zusammenarbeitete. Ziegler, der von 1967 bis 1983 sowie auch später für eine weitere Periode dem Nationalrat angehörte, war von Beginn weg als kompromissloser Vertreter der Anliegen der afrikanischen, asiatischen und lateinamerikanischen Länder bekannt. Allerdings vertrat er stets eine ebenso kompromisslos sozialistische Position, ungeachtet der heterogenen politischen Systeme in Ländern des Südens. ${ }^{165}$

Der Kontakt zwischen den Initianten und ersten Aktivistinnen und Aktivisten der EvB auf der einen und Ziegler auf der anderen Seite fand zunächst auf wissenschaftlicher Ebene statt. Ziegler gehört zu den seltenen Schweizer Wissenschaftlern, die in den 1960er-Jahren zu und in Afrika geforscht und zu den ersten in der Schweiz, die sich dazu ausserhalb der klassischen, noch im Kolonialismus verhafteten Völkerkunde etabliert hatten. ${ }^{166}$ So gehörte er ab 1965 zum Dozentenstab des Institut africain in Genf und stand in regem Austausch mit Roy Preiswerk und Pierre Bungener, und zwar noch bevor die „Erklärung von Bern“ aufgesetzt wurde. ${ }^{167}$ In den 1970er-Jahren trafen sich die Leute aus dem Umfeld des Instituts jeweils am Samstagabend in Preiswerks Haus. Zu diesen Gästen gehörte nicht nur Ziegler, sondern etwa auch der ghanaische spätere UNO-Generalsekretär Kofi Annan, der damals am Institut universitaire des hautes études internationales studierte. ${ }^{168}$ Bereits in den 1960er- und erst recht in den 70er-

162 Siehe dazu Mario Careras Lebenslauf auf der Webseite der SP Schweiz (https://www.sp-ps. ch/sites/default/files/.../cv_carera2012.pdf) (13.9.2017).

163 S. Howald: Dieses kostbare Gut, 18.

164 Siehe dazu Rudolf Strahms Biografie auf der Webseite des Eidgenössischen Parlaments (https://www.parlament.ch/de/biografie?CouncillorId=219) (13.9.2017).

165 J. Wegelin: Jean Ziegler, 134-135

166 Ebd., 100.

167 Ebd., 80.

168 Ebd., 147. 
Jahren bewegte sich Jean Ziegler auf internationalem Parkett, während die Deutschschweizer Dritte-Welt-Aktivisten in Bern und Zürich im nationalen Umfeld verhaftet blieben. Dies sollte sich sowohl auf politischer wie auch auf publizistischer Ebene zeigen.

Ziegler lehrte auch Entwicklungssoziologie an der Universität Bern, wo er 1967 die venia legendi für Soziologie der Entwicklungsländer erhielt. ${ }^{169}$ In Bern zählte Rudolf Strahm zu seinen Studenten aber auch zahlreiche andere Personen, die später schweizweit bekannt wurden. ${ }^{170}$ Durch seine Berner Vorlesungen führte Ziegler in den späten 1960er- und 70er-Jahren eine ganze Generation Schweizer Akademikerinnen und Akademiker in die Entwicklungssoziologie ein. ${ }^{171} \mathrm{Er}$ konnte seine Studierenden jedoch nicht dazu bewegen, ihm in seiner Radikalität zu folgen. So wenig Ziegler 1964 die zwar keynesianischen, aber doch grundsätzlich marktwirtschaftlichen Forderungen Prebischs unterstützte, so wenig machte er in den 1970er-Jahren den ideellen Wandel hin zum von Kleinbauern betriebenen biologischen Landbau mit. So blieb Ziegler im schweizerischen Parlamentsbetrieb auf eigentümliche Weise stets die zentrale, herausragende und einsame Figur für die Anliegen der ärmeren Staaten im globalen Süden. ${ }^{172}$

Doch auch in den Anfangsjahren, nach der Übergabe der „Erklärung von Bern“ an den Bundesrat, ist der Name Ziegler merkwürdig absent. Zu bürgerlich und zu national begrenzt scheint die Bewegung um die EvB für Ziegler gewesen zu sein. Als die Aktivistinnen und Aktivisten im Umfeld der EvB etwa 1970 die Konferenz im Bundeshaus in Bern planten, scheint Ziegler weder bei der Organisation involviert gewesen zu sein noch später der Konferenz beigewohnt zu haben. Die grundsätzlich marktwirtschaftliche Haltung der Erklärung von 1968, die lediglich die Umsetzung der Prebisch-Singer-Anliegen forderte, sowie das baldige Umschwenken der Bewegung auf grüne bzw. landwirtschaftliche Anliegen dürfte Erklärung genug sein für das Fehlen Zieglers im Schweizer Fair-TradeDiskurs. Doch es gab dafür auch noch weitere, persönliche Gründe. So plante Ziegler zu Beginn der 1970er-Jahre eine Publikation zu Entwicklungsfragen, zu der Rudolf Strahm und der Journalist und spätere Sekretär des Schweizerischen Gewerkschaftsbundes Beat Kappeler Artikel beisteuerten. Als 1976 Zieglers Buch „Une Suisse au-dessus de tout soupçon“ herauskam, erkannten Strahm und Kappeler mit Erstaunen ihre eigene Arbeit wieder. ${ }^{173}$ Somit ist die frühe publi-

169 Siehe dazu das Verzeichnis der Dozenten der Universität Bern (http://biblio.unibe.ch/digibern/dozenten_uni_bern.pdf) (24.4.2018).

170 A.-M. Holenstein-Hasler, R. Renschler, R. H. Strahm: Entwicklung heisst Befreiung, 118.

171 J. Wegelin: Jean Ziegler, 76-79.

172 Ebd., 134-135.

173 Ebd., 67. Wobei Strahm als Mitarbeiter auf dem Buchdeckel genannt wird. 
zistische Arbeit Strahms und auch Kappelers in das Werk Zieglers eingeflossen. Gleichzeitig fand hier aber auch bereits die offizielle Trennung statt: Strahms und Kappelers Texte waren bereits 1974 in der von der EvB herausgegebenen Publikation „Schweizer Kapital und Dritte Welt“ erschienen. ${ }^{174}$ Damit hatte sich die EvB klar zur eigenen Kraft ohne zieglerschen Sukkurs gemacht. Diese Anekdote zeigt auf, wie nah sich Ziegler und die „Jugendfraktion“ der EvB intellektuell zu Beginn der 1970er-Jahre noch standen. In den Jahren darauf sollten sie sich jedoch nicht nur thematisch voneinander entfernen, sondern - aufgrund von Zieglers Plagiat auch persönlich. ${ }^{175}$

Wichtiger für die weitere Entwicklung der Schweizer Fair-Trade-Bewegung waren andere Politiker. Die wichtigste Kontaktperson für die EvB war Walter Renschler, der 1967 bis 1987 als SP-Nationalrat und zweimal als Präsident der Kommission für auswärtige Angelegenheiten wirkte. ${ }^{176}$ Nach 1968 amtierte er als Vizepräsident des säkularen Hilfswerks Helvetas, gemeinsam mit Ruth Dreifuss sass er im Stiftungsrat des 1981 gegründeten Solifonds. ${ }^{177}$ Er und Regula Renschler, ab 1974 EvB-Sekretärin, waren nach 1962 mehrere Jahre verheiratet und verbrachten 1966 gemeinsam ein Jahr in Afrika. ${ }^{178}$ Walter Renschler war promovierter Ökonom und in der Bundespolitik in der Entwicklungspolitik aktiv. Er wurde unterstützt von seiner Kollegin Lilian Uchtenhagen, die 1971 in den Nationalrat gewählt wurde. Auffällig ist, dass sie beide promovierte Ökonomen waren und damit wie Rudolf Strahm zur Generation der aktivistischen Wirtschaftswissenschaftler der Zeit um 1968 zählten. Doch anders als Ziegler waren Nationalräte wie Renschler oder Uchtenhagen nicht alleinige und kompromisslose Advokaten der Dritten Welt. Zwar hatte sich Renschler bereits während des Studiums für die Dritte Welt interessiert und Afrika bereist, trotzdem machte die Entwicklungspolitik nur einen kleinen Teil seiner Agenda aus. Renschler wurde später wie Ruth Dreifuss insbesondere als Gewerkschaftsvertreter national bekannt. Rudolf Strahm wiederum sollte das Thema Entwicklungspolitik mit dem Ende des Nord-Süd-Dialogs und dem Anbruch der „conservative counterrevolution“ zu Beginn der 1980er-Jahre richtiggehend an den Nagel hängen und sich neuen Themen zuwenden. ${ }^{179}$

174 Kappeler, Beat; Strahm, Rudolf H.: Schweizer Kapital und Dritte Welt (Zürich 1974).

175 J. Wegelin: Jean Ziegler, 67.

176 Degen, Bernard: Renschler, Walter, in: Marco Jorio (Hg.): Historisches Lexikon der Schweiz (Basel 2002-2014) http://www.hls-dhs-dss.ch/textes/d/D6546.php (19.8.2010).

177 S. Howald: Dieses kostbare Gut, 25.

178 A.-M. Holenstein-Hasler, R. Renschler, R. H. Strahm: Entwicklung heisst Befreiung, 88.

179 J. Toye, R. Toye: UN and Global Political Economy, 254. 
Bezeichnend ist somit, dass die EvB nicht über eine eigentliche Vertreterin bzw. einen Vertreter in der Bundespolitik verfügte, sondern thematisch so breit gefächert war, dass sie bei verschiedenen Bundespolitikerinnen und -politikern Anknüpfungspunkte fand. So war etwa der Zürcher EVP-Nationalrat Heinrich Schalcher Stiftungsratspräsident des Fibl und setzte sich in der Bundespolitik stark für die biologische Landwirtschaft ein. ${ }^{180}$ Wie bereits erwähnt, ging die EvB auch gleich von Beginn weg eine „unheilige Allianz“ mit dem Republikaner James Schwarzenbach ein, als es darum ging, das Gesetz über die Entwicklungszusammenarbeit zu prägen. ${ }^{181}$ Während es sich bei der Zusammenarbeit zwischen Schwarzenbach und Strahm um eine offen deklarierte Zusammenarbeit handelte, pendelte sich der implizite Konsens zwischen den Vertretern der Dritte-Welt-Bewegung - welche das Konzept Small is beautiful vertraten - und den konservativen Vertretern der Landwirtschaft sowie den Gegnern eines Beitritts der Schweiz zu europäischen oder internationalen Organisationen in der Folge ein. Das Resultat war eine die Schweiz prägende „unheilige Allianz linker Entwicklungspolitiker und der nationalen Rechten““ ${ }^{182}$ Wie erwähnt brachte die Dritte-Welt-Bewegung anlässlich der interkonfessionellen Konferenz 1970 im Bundeshaus ihre Vorbehalte gegenüber dem Beitritt der Schweiz zu internationalen Organisationen vor:

Die Schweiz sollte keine handelspolitischen Abmachungen mit anderen Industrieländern treffen, welche die Absatzbedingungen in der Schweiz von nicht-subventionierten Produkten aus Entwicklungsländern erschweren. ${ }^{183}$

So formulierte die Dritte-Welt-Bewegung bereits kurz nach 1968 eine nationale politische Haltung, die dazu führte, dass in den kommenden Jahrzehnten ein impliziter politischer Konsens mit der nationalkonservativen, auf politische Neutralität und landwirtschaftliche Autarkie beharrenden Bewegung bestand. Diese „unheilige Allianz“ zeigte sich wie vorne erwähnt erstmals in der Zusammenarbeit mit James Schwarzenbach im Rahmen der Ausarbeitung des Bundesgesetzes über die internationale Entwicklungszusammenarbeit und humanitäre Hilfe, das 1976 zur Abstimmung kam. ${ }^{184}$ Sie trat weiter zutage bei der Referendumsabstimmung über den Bundesbeschluss betreffend ein Abkommen zwi-

180 U. Eichenberger: Ökologie und Selbstbestimmung.

181 Siehe dazu Kapitel 3.6: „Weniger nehmen“: Abschied von der Makroökonomie.

182 C. W., „Soziale Befreiung“ gegen Entwicklungszusammenarbeit, NZZ, 29.5.1981.

183 H. Schmocker, M. Traber: Schweiz-Dritte Welt, 109.

184 Siehe dazu in der Systematischen Rechtssammlung des Bundes das Bundesgesetz über die internationale Entwicklungszusammenarbeit und humanitäre Hilfe vom 19.3.1976 (https://www. admin.ch/opc/de/classified-compilation/19760056/index.html) (13.9.2017) 
schen der Schweiz und der Internationalen Entwicklungsorganisation (IDA) über ein Darlehen von 200 Millionen Franken, die im selben Jahr vom Volk abgelehnt wurde, und sie sollte Ende der 1970er-Jahre und zu Beginn der 1980er-Jahre bei Volksinitiativen wie der Futtermittelinitiative oder der Kleinbauerninitiative neu zum Tragen kommen. ${ }^{185}$ Die Bewegung hat ihre ablehnende Haltung gegenüber internationalen Organisationen zu Beginn der 1980er-Jahre sogar noch verstärkt. Zur Frage des Beitritts der Schweiz zur EWG liess die EvB 1971 ihre erste Auftragsstudie erstellen. Darin wurde etwas utopisch gefordert, dass die Schweiz nur der EWG beitreten solle, falls sie sich darin als Anwältin der Entwicklungsländer positionieren würde. ${ }^{186}$ Ebenfalls forderte die Bewegung 1970 im Bundeshaus ursprünglich noch, die Schweiz solle sich an zusätzlichen Aufstockungen der IDA beteiligen. ${ }^{187}$ Diese Uneinigkeit sollte sich in den folgenden Jahren zu einer klaren Ablehnung des Schweizer Beitritts sowohl zu europäischen wie auch zu BrettonWoods-Institutionen verdichten. In der Abstimmung über das Darlehen der Schweiz an die IDA gab die EvB 1976 - genau wie die meisten Schweizer Hilfswerke - noch Stimmfreigabe durch, und nur die Schweizerische Arbeitsgruppe für Entwicklungspolitik, die Safep, die radikalere Gruppierung der „Jugendfraktion“, empfahl ein klares Nein. ${ }^{188}$ Die offiziellen Hilfswerke gaben sich im politischen

185 Siehe dazu auf der Webseite der Schweizerischen Bundeskanzlei Rubrik „Volksabstimmungen“, Bundesbeschluss vom 20.6.1975 betreffend ein Abkommen zwischen der Schweiz und der Internationalen Entwicklungsorganisation (IDA) über ein Darlehen von 200 Millionen Franken, abgelehnt am 13.6.1976 (https://www.admin.ch/ch/d/pore/va/19760613/index.html) sowie die Rubrik „Volksinitiativen“, Eidgenössische Volksinitiative „gegen übermässige Futtermittelimporte und Tierfabriken sowie für bestmögliche Nutzung des einheimischen Bodens“, zurückgezogen für einen indirekten Gegenvorschlag am 28.10.1983 (https://www.admin.ch/ch/d/pore/ vi/vis130.html) und Eidgenössische Volksinitiative „für ein naturnahes Bauern - gegen Tierfabriken (Kleinbauern-Initiative)“, abgestimmt am 4.6.1989 (https://www.admin.ch/ch/d/pore/vi/ vis167.html) (14.4.2018).

186 A. Wagner: EWG und Dritte Welt.

187 H. Schmocker, M. Traber: Schweiz-Dritte Welt, 92.

188 SozArch, EvB, Ar 430.62.8. IDA: Rundbrief 1976/1, Beilage, EvB, Ar 430.62.8. IDA: safep Rundbrief 1 und 2/1976, Mai 1976. In den Jahren darauf sollte sich die Bewegung jedoch klar auf den Nichtbeitritt der Schweiz zu den Bretton-Woods-Institutionen einigen. So ergriffen die Hilfswerke 1991 gemeinsam das Referendum gegen den Beitritt der Schweiz zu den BrettonWoods-Institutionen Weltbank und Internationaler Währungsfonds. Siehe Bosshard, Peter: Internationaler Währungsfonds (IWF), in: Marco Jorio (Hg.): Historisches Lexikon der Schweiz (Basel 2002-2014) http://www.hls-dhs-dss.ch/textes/d/D26208.php (24.1.2007). Der seit Beginn der 1970er-Jahre bestehende implizite Konsens, die „unheilige Allianz“ zwischen dem tiersmondistisch-grünen und dem nationalkonservativen Lager, sollte in seinem ganzen Ausmass 1992, bei der Abstimmung über den Beitritt der Schweiz zum EWR, zu Tage treten, als die Grüne Partei die Nein-Parole beschloss und damit gemeinsam mit der nationalkonservativen Schweizerischen Volkspartei einen Abstimmungserfolg herbeiführte. Siehe Brassel-Moser, Ruedi: Grüne 
Prozess vorsichtig. Sie versuchten, eine Zusammenarbeit mit der politischen Rechten zu vermeiden und beschlossen unter anderem auch deshalb etwa bei der Abstimmung über den Kredit an die IDA Stimmfreigabe. ${ }^{189}$ Doch die Basis liess sich dadurch nicht beirren. So schrieb ein Ehepaar, das sich für die Anliegen der EvB stark machte, 1980 in Bezug auf die damalige Abstimmung in einem Leserbrief: „Es ist nun höchste Zeit, dass der Bundesrat und namentlich unsere Parlamentarier in Bern die wahre Einstellung vieler Bürger endlich zur Kenntnis nehmen und ihre Politik darnach richten." ${ }^{190}$ Ende der 1970er-Jahre, nicht zuletzt im Zuge der Diskussionen um und der darauffolgenden Ablehnung des IDA-Kredits durch eine Mehrheit der Stimmbürgerinnen und Stimmbürger, setzte sich an der Basis der Bewegung die Ablehnung des Beitritts der Schweiz zu internationalen Organisationen und der implizite, auf dem gemeinsamen Nenner des Kleinbauern beruhenden Konsens durch, der in der Folge die schweizerische Aussenpolitik prägen sollte.

\subsection{Für Protektionismus und Autarkie, gegen Freihandel und Grosskonzerne: das Fair-Trade-Konzept zu Beginn der 1980er-Jahre}

Mit dem Anbruch der 1980er-Jahre trat das „neue“, paraakademische Fair-TradeKonzept, das sich in den 1970er-Jahren herausgebildet hatte, seinen institutionellen Siegeszug an. Von aussen sichtbar war dies etwa in der Aktion M-Frühling, an der nebst der Frauenfelder „Bananenfrau“ Ursula Brunner auch die EvB-Sekretärin Anne-Marie Holenstein als Migros-Genossenschafterinnen beteiligt war. ${ }^{191}$ Der Schweizer Supermarkt Migros war nicht nur genossenschaftlich organisiert, sondern unterhielt mit dem Gottlieb-Duttweiler-Institut in Rüschlikon sogar einen eigenen Think-Tank, der Raum für Diskussionen und Publikationen bot. ${ }^{192}$ Brunner, unterdessen FDP-Grossrätin im Kanton Thurgau, kandidierte für einen Sitz in der Verwaltungsdelegation des Migros-Genossenschaftsbundes. ${ }^{193}$ Holenstein steuerte einen Artikel für die Publikation M-Frühling. Vom Migrosaurierer zum menschlichen Mass bei, die mit dem deutschen Begriff „menschliches

Parteien, in: Marco Jorio (Hg.): Historisches Lexikon der Schweiz (Basel 2002-2014) http://www. hls-dhs-dss.ch/textes/d/D17413.php (28.7.2015).

189 SozArch, EvB, Ar 430.62.8. IDA: Rundbrief 1976/1, Beilage.

190 SozArch, EvB, Ar 430.62.8. IDA: R. und W. B., Leserbrief an den „Beobachter“, 17.5. 1980.

191 B. Mahler: ,umdenken - umschwenken', 75.

192 Ebd.

193 Ebd., 75. 
Mass“ wiederum sowohl an E.F. Schumacher wie unbeabsichtigt an Wilhelm Röpke anknüpfte. ${ }^{194}$ Doch auch intern, innerhalb der verschiedenen Dritte-WeltOrganisationen, erfolgten institutionelle Prozesse, die erst Jahre später für die Öffentlichkeit sichtbar wurden. Wie weiter oben gezeigt, befragte auch die OS3 ihre Mitglieder 1979 brieflich, ob sie sich eine kommerzielle Ausweitung auf die Grossverteiler vorstellen könnten. ${ }^{195}$ Auch intern fanden in der EvB erste Schritte in Richtung einer institutionellen Festigung des Fair-Trade-Konzepts statt. So gab Anne-Marie Holenstein im Namen der EvB 1980 erstmals ein juristisches Kurzgutachten in Auftrag, das die Einführung eines entwicklungspolitischen Labels prüfen sollte. ${ }^{196}$ Die EvB führte ab 1980 die Kampagne „Globaler Supermarkt und Hunger“ durch, und die Koordinatorengruppe der Kampagne diskutierte die Idee, ein Gütezeichen oder eben ein „Schlechtezeichen“ zu lancieren. ${ }^{197}$ Wie die in den 1970er-Jahren entstandene Dominanz der Idee der „Peripherie im Inland“ in diesem Kontext zum Tragen kam und wie die ursprünglichen Slogans The Limits to Growth und Small is beautiful nun, zu Beginn der 1980er-Jahre, in den Umweltschutz übersetzt wurden, zeigen die von der Arbeitsgruppe ausgearbeiteten Kriterien, welche einem „Güte- oder Schlechtezeichen“ zugrundeliegen sollten:

3. Kriterien für Verleihung des Güte- oder Schlechtezeichens

1. Ökologie

2. Soziale Faktoren (in IL und EL)

3. Gesundheit ${ }^{198}$

Die Ökologie, der Umweltschutz, war 1980 zum Hauptpunkt des Programms geworden, das die EvB verfolgte. Die Entwicklungsländer (EL) werden erst in Punkt 2 genannt, aber nur in Verbindung mit der Idee der „Peripherie im Inland“: Unterdessen konnten die Entwicklungsländer kaum mehr erwähnt werden ohne

194 A.-M. Holenstein: Jute statt Plastik.

195 SozArch, Claro,1010.12. OS3 Gründung: Mario Carera, OS3 bald im breiteren Handel?, November 1979.

196 SozArch, EvB, Ar 430.41.1. Textilien, Mappe 3: Koordinatorengruppe Aktion Globaler Supermarkt und Hunger. Aktion „Label“-Zeichen/Aktion Gütezeichen-Schlechtezeichen, AnneMarie Holenstein, 30.5.1980, Fragenkatalog.

197 SozArch, EvB, Ar 430.41.1. Textilien, Mappe 3: Koordinatorengruppe Aktion Globaler Supermarkt und Hunger. Aktion „Label“-Zeichen/Aktion Gütezeichen-Schlechtezeichen, AnneMarie Holenstein, 30.5.1980, Fragenkatalog.

198 SozArch, EvB, Ar 430.41.1. Textilien,. Mappe 3: Koordinatorengruppe Aktion Globaler Supermarkt und Hunger. Aktion „Label“-Zeichen/Aktion Gütezeichen-Schlechtezeichen, AnneMarie Holenstein, 30.5.1980, Fragenkatalog. 
Hinweis auf die „Armen“ im Inland bzw. im Industrieland (IL). Als Ausblick auf die Entwicklung der kommenden Jahrzehnte ist auch Punkt 3 spannend, also das Kriterium „Gesundheit“. Hier wird auf eine andere Art sichtbar, worüber Al Imfeld kurze Zeit später schreiben würde: „Zwischen Kopf und Bauch geht da anderes vor."199 Die Idee des gerechten Nord-Süd-Handels war vom Kopf in den Bauch gerutscht. Aus dem politischen Bürger, dem erweckten Christen, der bereit war, „Privilegien aufzugeben“, war in den 1970er-Jahren der politische Konsument geworden, der ungeniessbaren Pulverkaffee kaufte. Nun, 1980, noch bevor eine neoliberale Ära auf internationaler politischer Ebene so richtig in Gang gekommen war, trat im Fair-Trade-Konzept der Dritte-Welt-Bewegung der Individualismus, „die Eigeninteressen mittelständischer Hausfrauen“, der „Rückzug ins Private“ zum Vorschein. ${ }^{200}$ Wie ein grobschlächtiger erster Prototyp des homo oeconomicus aus dem methodologischen Individualismus der 1950er-Jahre gebärdete sich der Fair-Trade-Konsument der 1980er-Jahre als jemand, der gemäss Bauchgefühl seinen Eigennutzen maximierte. Seine eigene Gesundheit, seine Umwelt und sehr bald auch schon sein eigener Genuss und die gute Qualität der Fair-Trade-Produkte durften nicht vernachlässig werden, und der Aufpreis, mit dem er sein schlechtes Gewissen beruhigte, war dabei so klein, dass er nicht ins Gewicht fiel. Kein Wunder lesen sich die ersten juristischen Studien zur Einführung eines entwicklungspolitischen Labels im Rückblick wie gründliche Fehleinschätzungen, stützten sich die sehr genau und sorgfältig arbeitenden beiden Juristen doch auf Literatur und Dokumente der 1970er- und 60er-Jahre. So erachtete der erste Jurist die Einführung eines „Güte- oder Schlechtezeichens“ als juristisch hochproblematisch. Insbesondere bei einem „Schlechtezeichen“ rechnete er mit Klagen der entsprechenden Hersteller. ${ }^{201}$

1981 verfassten zwei von der OS3 beauftragte Ökonomen eine Studie, in der sie die Idee eines „Labels“ diskutierten und die entsprechenden Kriterien erarbeiteten. ${ }^{202}$ Nachdem die Schweiz im Juni 1981 den Konsumentenschutzartikel angenommen hatte, gab Hans Ott, der eigentlich beim katholischen Hilfswerk Brot für Brüder arbeitete, aber auch dem Verwaltungsrat der OS3 angehörte, den Auftrag zu einer weiteren, grösser angelegten Studie, die von Brot für Brüder fi-

199 A. : Die „Erklärung von Bern“ in der Krise.

200 K. J. Kuhn: Entwicklungspolitische Solidarität, 419, A.-M. Holenstein-Hasler, R. Renschler, R. H. Strahm: Entwicklung heisst Befreiung, 289.

201 SozArch, EvB, Ar 430.41.1. Textilien, Mappe 3: Adrian Stahel an EvB, 18.8.1980 Kurzgutachten [zur Einführung eines Güte-Schlechte- oder Labelzeichens in der Schweiz].

202 Stetter, Hilmar; Vatter, Thomas: Importförderung, entwicklungspolitisch begriffen (Sonceboz 1981). 
nanziert wurde. ${ }^{203}$ Darin brachte der Autor, ein Basler Jurist, zwar keine juristischen Bedenken mehr an, da er lediglich ein „Label“ und nicht mehr ein wertendes Güte- oder Schlechtezeichen zu untersuchen hatte. Doch aufgrund der ihm zur Verfügung gestellten Unterlagen, die zu Teilen noch aus der Feder von Rudolf Strahm und aus den 1970er-Jahren stammten, kam er zu einem Schluss, der aus heutiger Sicht überrascht:

Entwicklungspolitisch sind die Nahrungsmittelimporte umstritten. [...] Kaffee, Tee und Reis [...] erweisen sich für ein Label ebenfalls als wenig geeignet. [...] Obwohl naheliegend, ist die Einführung eines Labels bei Nahrungsmitteln als eher ungünstig zu betrachten. Ein Label erscheint bei Non-Food-Artikeln eher geeignet. ${ }^{204}$

Der Jurist Christoph Lanz hatte in sechs Monaten und gegen Bezahlung eine nüchterne, wissenschaftliche Studie verfasst. Er stützte sich dabei nicht nur auf interne Dokumente der OS3, sondern auch etwa auf eine Studie des International Trade Center (ITC) in Genf zu Anliegen von Entwicklungsländern bezüglich Exportförderung. Das ITC entstand 1964 als Bindeglied zwischen der UNCTAD und dem GATT und hatte den Auftrag, Studien zur Förderung des Aussenhandels von Entwicklungsländern zu generieren. ${ }^{205}$ In der von Lanz verwendeten Studie äusserten die Vertreter von Entwicklungsländern auch zwei Jahrzehnte nach der ersten UNCTAD-Konferenz 1964 weiterhin den Wunsch, verarbeitete Produkte zu exportieren. Zudem nahm Lanz Rudolf Strahm, der bei der Gründung der Genossenschaft die Kriterien für die Importförderung der OS3 ausgearbeitet hatte, beim Wort:

- möglichst arbeitsintensiv

- mit den lokalen Gegebenheiten angepasste Technologie

- in kleinindustriellen Werkstätten oder Betrieben

- Material aus lokalen Rohstoffen

- das Produkt soll der einheimischen Kultur entsprechen

- das Produkt darf die lokale Versorgung mit Gütern (oder Nahrungsmittel) nicht gefährden

- die Produktion sollte möglichst dezentral und genossenschaftlich organisiert sein

- Produktion möglichst umweltschonend

203 SozArch, EvB, Ar 430.41.1. Mappe 3: Ein entwicklungspolitisches Label - Chancen und Probleme, Ch. Lanz, 1983. Siehe dazu auf der Webseite der Schweizerischen Bundeskanzlei die Rubrik „Volksabstimmungen“, den Bundesbeschluss vom 10.10.1980 über die Volksinitiative „zur Absicherung der Rechte der Konsumenten“ (Gegenentwurf) (https://www.admin.ch/ch/d/pore/ va/19810614/) (14.4.2018).

204 SozArch, EvB, Ar 430.41.1. Mappe 3: Ein entwicklungspolitisches Label - Chancen und Probleme, Ch. Lanz, 1983.

205 Siehe zum ITC http://www.intracen.org/default.aspx (9.3.2018). 
- Produktion möglichst energiesparend

- Produktion unter humanen Arbeitsbedingungen

- möglichst viele soziale Sicherheiten

- Möglichkeit zu gewerkschaftlicher Tätigkeit

- Möglichkeit zur Berufsbildung im Betrieb selbst

- Anstreben längerfristiger, regelmässiger Exporte ${ }^{206}$

Lanz setzte den von der OS3 geprägten Begriff des ,idealen Produkts aus einem 3. Welt-Land“ - für das die Kriterien erarbeitet wurden - in Anführungszeichen. Damit zeigte er, dass er das Bedürfnis der damaligen Bewegung nach einem „idealen Produkt“ hinterfragte und jenes nach Idealität an sich zur Diskussion stellte. Er riet zwar nicht von der Einführung eines „entwicklungspolitischen Labels“ ab, doch brachte er Vorbehalte an, die an die Dokumente aus den Anfangszeiten der EvB erinnern und in den individualistischen 1980er-Jahren ungehört verhallten: Unter dem Titel „Das entwicklungspolitische Kriterium“ schrieb Lanz: „Meines Erachtens stellt sich hier mit diesem Kriterium die Kardinalsfrage des ganzen Projekts.“ Und:

\begin{abstract}
Leistet hier ein Label somit nicht einer falschen Entwicklung, nämlich der Förderung eines Handelsaustausches, dessen Gewinn letztlich den Falschen zugute kommt, Vorschub? Wir kommen nicht darum herum, den Welthandel als eine Tatsache zu betrachten. Aber wir müssen alles daran setzen, dass er unter möglichst gerechten Bedingungen abläuft. Ein Label wäre ein Mittel dazu. Dies schliesst die fortdauernde Kritik an den herrschenden Zuständen nicht aus, im Gegenteil. ${ }^{207}$
\end{abstract}

Lanz hatte luzide erfasst, dass gerade die „fortdauernde Kritik an den herrschenden Zuständen“, wie sie in der Erklärung von 1968 und im Vorfeld dazu erfolgt war, Gefahr lief, von einem kommerziellen Label und einem „idealen Produkt“ verdrängt zu werden. Der spätere Siegeszug des „Labels“ sollte mit einem Verschwinden der „Kritik an den herrschenden Zuständen“ einhergehen bzw. genauer: mit dem oben ausgeführten Konzeptwechsel zu einer statischen Sicht des Südens (und des Nordens). Das Label sollte im Gegenteil die herrschenden Zustände, nämlich die Rolle der Kleinbauern im Süden als Rohstofflieferanten, beschönigen und zementieren. Die Bewegung sehnte sich nach einem „Ideal“, das sich schliesslich im Kleinbauern und seinem begrenzten Warenkorb an tropischen Nahrungsrohstoffen manifestieren sollte. Diese „Idealisierung“, die der

206 SozArch, EvB, Ar 430.41.1. Mappe 3: Ein entwicklungspolitisches Label - Chancen und Probleme, Ch. Lanz, 1983.

207 SozArch, EvB, Ar 430.41.1. Mappe 3: Ein entwicklungspolitisches Label - Chancen und Probleme, Ch. Lanz, 1983. 
Jurist Lanz 1983 voraussah, sollte sich bewahrheiten und zu Beginn des 21. Jahrhunderts vom Afrika-Ökonom Paul Collier kritisiert werden:

But the problem with it [Fair Trade], as compared with just giving people the aid in other ways, is that it encourages recipients to stay doing what they are doing - producing coffee. A key economic problem for the bottom billion is that producers have not diversified out of a narrow range of primary commodities. [...] They get charity as long as they stay producing the crops that have locked them into poverty. ${ }^{208}$

Sukkurs erhielt Collier ausgerechnet vom bekanntesten britischen Fair-TradePionier Roy Scott, der 1973 für Oxfam die Alternative Importgesellschaft Bridge aufgebaut hatte. Scott, der Ende der 1970er-Jahre frustriert Oxfam verlassen hatte, nannte das Fair-Trade-Konzept im 21. Jahrhundert „rigmarole“, Geschwätz:

Bizarre isn't it, you get countries away from cash crops by arguing value should stay with the producer - and now we have the wonderful rigmarole about how great all these food products are - all that is going on is we in Europe import the raw materials and do all the processing. ${ }^{209}$

Dieses „Geschwätz“, diese Idealisierung eines eigentlich kolonial-statischen Schicksals (,to stay doing what they are doing“) und das Abdriften des Fair-TradeKonzepts der NGOs, das zuerst der akademischen Ökonomie verpflichtet war, in ein eigenes, paraakademisches Konzept, oder gar der Rückfall in koloniale Muster, werden in dieser Kritik überdeutlich. Interessant ist wiederum, dass dieses paraakademische Fair-Trade-Konzept in keiner Weise der Küche einer kleinen, marginalisierten Gruppe entsprang, sondern im Gegenteil einem breiten und impliziten Konsens in der Bevölkerung entsprach. Dieser implizite Konsens sollte sich in der Schweiz wiederholt in angenommenen oder knapp angenommenen Volksabstimmungen und eidgenössischen Volksinitiativen oder Referenden zu den Themen Landwirtschaft, Umweltschutz und internationalen Organisationen zeigen. Während die erste Generation der EvB um den Prebisch-Berater Christoph Eckenstein und den frisch diplomierten Ökonomen Rudolf Strahm noch die jüngsten wirtschaftswissenschaftlichen Resultate und Debatten vertreten hatte, fand der Abschied von der Makroökonomie gleichzeitig mit einer Einbettung der Bewegung in die gesellschaftliche Mitte statt.

Für die Beobachtung, dass das neue Fair-Trade-Konzept in der gesellschaftlichen Mitte eingebettet war, spricht auch, dass die Geschichte der Einführung des Labels durch die offiziellen institutionellen Trennlinien hindurchmäandriert und

208 P. Collier: The Bottom Billion, 163.

209 M. Anderson: History of Fair Trade, 227. 
im Rückblick als ein Gemeinschaftswerk der Dritte-Welt-Bewegung als Ganzes angesehen werden muss. Im Anschluss an die ersten Ujamaa-Pulverkaffee-Verkäufe durch die AG3W und die EvB, die Bananenverkäufe der Frauenfelder Frauengruppe, das Entstehen von Dritte-Welt-Läden sowie die 1977 von der EvB initiierte Gründung der OS3 gab wiederum die EvB 1980 den Auftrag zu einem ersten juristischen Gutachten. Darauf folgte eine Studie der OS3. Dass die nächste Studie, die im Lauf des Jahres 1982 entstand, offiziell von Brot für Brüder finanziert wurde, kann mit den Finanzproblemen erklärt werden, die die EvB damals hatte, aber auch damit, dass das Hilfswerk zu den Trägern der OS3 gehörte. Das Konzept, das dem von den Hilfswerken zehn Jahre später lancierten Gütesiegel zugrunde lag, war in einer gemeinschaftlichen Diskussion, in zahlreichen Sitzungen, Tagungen, Workshops, in Korrespondenzen und Gesprächen entstanden. Es wurde beeinflusst von der internationalen paraakademischen Literatur, beinhaltete aber auch einen Schuss helvetisches Identitätsempfinden. Wie sehr sich die frühe Fair-Trade-Bewegung der Schweiz als einheitliche Gruppe sah, kommt denn auch in der ersten Informationsbroschüre zum Ausdruck, welche die OS3 nach der Gründung 1977 drucken liess:

In der Schweiz begann es 1973-75 mit dem Verkauf von mehreren Tonnen Pulverkaffee aus Tansania und von gerechter bezahlten Bananen in einigen Orten der Ostschweiz. [...] Seit 1974 entstanden gleichzeitig rund 30 Dritte Welt-Läden. Mit der Genossenschaft OS3 haben diese Aktionen nun eine breitere organisatorische Basis erhalten. ${ }^{210}$

Nachdem die Fair-Trade-Bewegung und die Umweltbewegung zusammengefunden hatten, stiessen Ende der 1970er-Jahre auch noch die Gewerkschaften dazu. $\mathrm{Zu}$ Beginn der 1980er-Jahre war somit eine neue, schlagkräftige Bewegung geboren. So nahmen 1980 rund 3000 Leute an einer Konferenz der verschiedenen entwicklungspolitischen Organisationen, dem entwicklungspolitischen Symposium in Bern, teil und demonstrierten eindrücklich die „Mobilisationskraft der Szene““.211 „Eine neue Lobby“ titelte die „Basler Zeitung“, und die NZZ beobachtete eine „unheilige Allianz linker Entwicklungspolitiker mit der nationalen Rechten“. ${ }^{212}$ Gemäss dem Urteil der NZZ war der Einfluss der „neuen Lobby“ im nationalen Parlament gerade aufgrund ihrer „unheiligen Allianz“ mit der sich in dieser Zeit formierenden nationalkonservativen Bewegung bedeutend.

210 SozArch, Claro 1010.2. OS3: Informationsbroschüre, 1.11.1977.

211 S. Howald: Dieses kostbare Gut, 20.

212 Heinz Däpp, Neue Lobby, Basler Zeitung, 2.6.1981, C. W, „Soziale Befreiung“ gegen Entwicklungszusammenarbeit, NZZ, 29.5.1981. 
Gleichzeitig wurde auch das Alternative Trading schleichend aufgegeben und es kam - so überraschend dies auch klingen mag - mit dem „Massenkonsum von Kleinbauernkaffee“ zu einer Annäherung an die Privatwirtschaft bzw. an die multinationalen Konzerne. ${ }^{213}$ Für kurze Zeit war die EvB selbst ein Unternehmen gewesen: Für den Einkauf des Ujamaa-Kaffees musste sie sich mit Zollformalitäten und Buchhaltung herumschlagen. ${ }^{214}$ Solange die NGOs Alternativen Handel propagierten und selber betrieben, waren sie den multinationalen Konzernen gegenüber weniger feindlich eingestellt. Erstens glaubte man damals noch tatsächlich daran, eine alternative Weltwirtschaft aufbauen zu können. ${ }^{215}$ Zweitens sass die EvB als Verkäuferin von Produkten sogar mit den Grosskonzernen im selben Boot. Die Energie wurde in den 1970er-Jahren darauf verwendet, das eigene Unternehmen zu gestalten, und nicht dazu, Kritik an anderen zu üben. Parallel zum Outsourcen des Unternehmertums an eine eigenständige Firma begann in der EvB der Feldzug gegen die multinationalen Konzerne. Der NestléProzess der AG3W von 1974 bis 1976, in den sowohl Rudolf Strahm wie der spätere Bundesrat Moritz Leuenberger als Rechtsanwalt der Aktivisten involviert waren, hatte den Auftakt zum „anticorporatism“ gegeben. ${ }^{216}$ Es folgte 1978 die Publikation der „Multi-Papers“. ${ }^{217}$ Von da an sollte sich die Kritik an multinationalen Unternehmen zur Kernkompetenz der EvB entwickeln. Je mehr sich die Möglichkeit eines alternativen Wirtschaftssystems auflöste und dieses auch von seinen Verfechtern aufgegeben wurde, umso intensiver wurde die Kritik an den multinationalen Unternehmen und umso mehr standen diese unter Beobachtung; auch die an sie gestellten Forderungen vermehrten sich. Die NGOs speisten sich zunehmend aus dem ,anticorporatism“ anstatt Alternativen vorzugeben. Je mehr sie eine Alternative verwarfen, umso stärker waren sie in ihrem Bestehenszweck abhängig von den multinationalen Unternehmen.

Interessanterweise wurde aus dieser ursprünglichen Kritik an privaten Grosskonzernen eine generelle Kritik an grossen, supranationalen Institutionen. Die Kritik an den Multis wurde gepaart mit der Kritik an der EWG und jener an den Bretton-Woods-Institutionen, wie der IDA. ${ }^{218}$ Bereits 1971 meldete die EvB gegen

213 R. Quaas: Fair Trade, 357.

214 Siehe dazu SozArch, EvB, Ar 430.27.1. Kaffee Ujamaa 73-77.

215 SozArch, EvB, Ar 430.10.2. Rudolf Strahm, Entwicklungspolitische Bewusstseinsbildung Thesen für die zukünftige Arbeit, undatiert.

216 T. Sasson: Milking the Third World.

217 Erklärung von Bern, Vereinigung für Solidarische Entwicklung: Die ,Multi-Papers‘.

218 SozArch, EvB, Ar 430.11.1. Mappe 4: Pressecommuniqué zum EWG-Beitritt der Schweiz, Ar 430.62. Internationaler Währungsfonds (IWF)/Weltbankgruppe, Ar 430.62.8. Mappe 1: Kampagne gegen den Kredit an die IDA 1976. 
einen Beitritt der Schweiz zum EWG entwicklungspolitische Bedenken an, 1976 stellte sie sich gegen einen Schweizer Kredit an die IDA, Mitte der 1980er-Jahre begann sie ihre Energie auf die Verhinderung des Beitritts der Schweiz zu den Bretton-Woods-Institutionen zu verwenden. Die fortlaufenden Kampagnen gegen den Bau von Staudämmen, welche die unheilvolle Verquickung der internationalen Organisationen, der multinationalen Unternehmen und der Regierungen der Industriestaaten symbolisierten, illustrieren diese Entwicklung sehr gut. Hier wurden die Bretton-Woods-Institutionen als Komplizen des big business gesehen. Die Bewegung warf den Bretton-Woods-Institutionen vor, Staudämme bzw. die Stromzufuhr von jenen Grosskonzernen sicherstellen zu wollen, die sich in Entwicklungsländern Profite erhofften. Sie warf den Bretton-Woods-Institutionen und Multis vor, Menschenrechte, Umweltschutz und traditionelle Wirtschaftsformen zu missachten. Das Umweltschutzargument wurde ebenso benutzt wie das Argument des menschlichen Masses (Small is beautiful), wobei das Ziel faktisch darin bestand, eine protektionistisch-nationale Volkswirtschaft in der Schweiz und die Autarkie der Entwicklungsländer in der Dritten Welt zu propagieren. Bereits 1975 äusserten die schweizerischen Hilfswerken in der Debatte um ein eidgenössisches Gesetz über die Entwicklungszusammenarbeit Misstrauen gegenüber wirtschaftlichen Beziehungen zwischen Nord und Süd:

Zunächst geht es darum, alle Beziehungen - vor allem wirtschaftlicher Natur - zu den Entwicklungsländern zu unterbinden, die einer eigenständigen Entwicklung der Dritten Welt abträglich sind..$^{219}$

Dieses Misstrauen hatte sich in eine gänzliche Ablehnung des Handels ausgewachsen. Aus Sicht der Bretton-Woods-Institutionen und der akademischen Ökonomie war das Problem zu Beginn der 1980er-Jahre jedoch genau andersrum gelagert. Die Politik des import substitution investment war insbesondere in afrikanischen Ländern, aber auch teilweise in Lateinamerika oder Indien gescheitert. $^{220}$ Südliche Ökonomen wie etwa Deepak Lal sprachen sich für eine liberale Aussenwirtschaftspolitik in diesen Ländern aus. ${ }^{221}$ Einzig in asiatischen Ländern, die - wie Dani Rodrik aufgezeigt hat - im Vorfeld eine sehr egalitäre Einkommensverteilung aufwiesen, hat das import substiution investment ein starkes Wirtschaftswachstum ausgelöst und aus vormals armen Entwicklungsländern wirtschaftliche Konkurrenz erwachsen lassen. ${ }^{222}$ Rodriks Forschung kommt der

219 A. Bänziger: Entwicklungsland Welt - Entwicklungsland Schweiz, 11.

220 P. Plickert: Wandlungen des Neoliberalismus, 245.

221 G. Austin: The Developmental State, 54.

222 Ebd., 56. 
Kritik aus der Dritte-Welt-Bewegung entgegen, dass Wirtschaftswachstum einzig einer lokalen Elite zugute komme, indem er aufgezeigt hat, dass das Vorhandensein von „wealthy elites“ Wirtschaftswachstum durch import substitution investment schlicht vereitelt hat. ${ }^{223}$

Internationale Konzerne hatten sich nach Zwangsnationalisierungen und Militärputschen aus manchen Entwicklungsländern zurückgezogen. Die alteingesessene Basler Handelsgesellschaft, um nur ein Schweizer Beispiel zu nennen, hatte trotz jahrzehntelanger Geschäftserfahrung in Afrika derartige Verluste eingefahren, dass sie sich in den 1980er-Jahren nach über einem Jahrhundert praktisch aus dem Afrika-Geschäft zurückzog. ${ }^{224}$ Das Problem waren aus Sicht der neoliberalen Ökonomen, die zu Beginn der 1980er-Jahre sowohl an den Universitäten wie auch bei den Bretton-Woods-Institutionen die Deutungshoheit gewannen, das Ausbleiben von Investitionen in Entwicklungsländer und die entsprechende Wachstumsschwäche, ausbleibende Innovationen und fehlendes Know-how, fehlende Spin-offs und zu wenig Beschäftigungsmöglichkeiten für gut Ausgebildete. ${ }^{225}$ Toye und Toye kritisieren allerdings, dass sich in den 1980erJahren bei den UN-Organisationen wie auch bei den Bretton-Woods-Institutionen die Ansicht durchsetzte, dass es den Entwicklungsländern einzig wegen interner Probleme wirtschaftlich schlecht gehe. Insbesondere den hohen Protektionismus der Entwicklungsländer selbst als Folge des Dogmas der infant industry protection monierten die internationalen Organisationen als internes Problem. ${ }^{226}$

In den 1960er-Jahren hatten die Aktivistinnen und Aktivisten immer wieder das Thema Arbeitslosigkeit in der Dritten Welt und die dringende Notwendigkeit des Wirtschaftswachstums als Bedingung für die Schaffung von Arbeitsplätzen betont. Fast schon apokalyptisch schrieb der Wirtschaftsethiker Arthur Rich in einer Studie für den ÖRK 1965: „Millionen junger Arbeitsloser [in den Entwicklungsländern] sind bereit, sich fanatischen Ideologien, die nach Gewalt rufen, hinzugeben.“227 Die ökonomische Machbarkeit des full employment hatte noch bis in die 1970er-Jahre auch die Dritte-Welt-Aktivisten geprägt. Doch hatte die Bewegung ihre eigenen Anliegen vergessen und das Thema Arbeitslosigkeit verschwand (zumindest für den Fall der Entwicklungsländer) von der Agenda. Gerade Entwicklungsländer, die viel in die Ausbildung investiert hatten, erlebten einen starken Braindrain, der nicht nur auf politische Instabilität zurückzuführen war, sondern auch schlicht auf mangelnde Beschäftigungsmöglichkeiten für

223 Ebd.

224 N. Stettler: Basler Handelsgesellschaft.

225 J. Toye, R. Toye: UN and Global Political Economy, 260.

226 Ebd., 261

227 A. Biéler: Gottes Gebot. 
Ärztinnen und Ärzte, Ingenieurinnen und Ingenieure. Insbesondere in Ländern, die sozialistische Verstaatlichungen, Militärcoups oder beides hinter sich hatten, blieben in den 1980er-Jahren Investitionen von privaten multinationalen Unternehmen trotz Auflagen der Bretton-Woods-Institutionen aus. ${ }^{228}$ Gleichzeitig waren multinationale Grosskonzerne - im Gegensatz zu kleinen und mittleren Unternehmen - die privaten Akteure, die sich das Risiko von Investitionen in Entwicklungsländern überhaupt leisten konnten. Daher unterstützten die BrettonWoods-Institutionen in Entwicklungsländern grosse Staudammprojekte, die das Investitionsklima, das sich beispielsweise durch eine gesicherte Stromzufuhr verbesserte, fördern sollten. Doch die Basis der Dritte-Welt-Bewegung wünschte sich grundsätzlich kein Wachstum in Entwicklungsländern, ebenso wenig wie die Errichtung von neuen Industrien oder sonstige Veränderungen der traditionellen Wirtschaft. Sie sah daher die wachstumsfördernde Wirkung von Investitionen multinationaler Unternehmen in den Entwicklungsländern nicht als etwas Positives, sondern betrachtete die Aktivitäten der multinationalen Unternehmen als nachteilig und, als weiterer negativer Punkt, als Imperialismus. ${ }^{229}$ So wurden die Bretton-Woods-Institutionen und die multinationalen Unternehmen zur Zielscheibe der Kritik der Bewegung. Diese Haltung wurde 1981 im „Entwicklungspolitischen Manifest für die 80er Jahre“ anlässlich des schweizerischen Symposiums der Solidarität am 31. Mai 1981 in Bern schriftlich festgehalten: ${ }^{230}$

\begin{abstract}
Wir sehen vor, den schweizerischen Beitritt zum Internationalen Währungsfonds (IWF) gegebenenfalls mit einem Referendum zu verhindern, wenn die Schweiz unsere entwicklungspolitischen Anliegen nicht berücksichtigt. [...] Wir planen konkrete Recherchen und Aktionen zu jener Geschäftspraxis schweizerischer multinationaler Konzerne in Entwicklungsländern, die nicht zur Befriedigung der Grundbedürfnisse beiträgt, sondern als Ausplünderungspolitik zu bezeichnen ist. ${ }^{231}$
\end{abstract}

„The Age of Alternatives“, wie die britische Dritte-Welt-Aktivistin Maggie Black das Jahrzehnt der 1970er-Jahre genannt hatte, war vorüber. Das Jahrzehnt, in dem die Utopie eines alternativen Handelssystems, eines alternativen Lebensstils, noch real erschienen war, war Geschichte. Vorbei war auch die Zeit, in der die westliche Dritte-Welt-Bewegung sich mit alternativen Entwicklungsformen für Entwicklungsländer beschäftigt hatte. Die entwicklungspolitische Bewegung der 1980er-

228 J. Toye, R. Toye: UN and Global Political Economy, 260.

229 Dezentrale: Alternativ-Katalog 3, 569, R. H. Strahm: Beziehungen Schweiz Dritte Welt.

230 SozArch, EvB, Ar 430.26.1. Mappe 2: Entwicklungspolitischen Manifest für die 80er Jahre, 1981.

231 SozArch, EvB, Ar 430.26.1. Mappe 2: Entwicklungspolitischen Manifest für die 80er Jahre, 1981. Siehe auch K. J. Kuhn: Entwicklungspolitische Solidarität, 346. 
Jahre - „resigniert, schuldig, ausgeliefert, machtlos“ - hatte keine Alternative mehr zu präsentieren. ${ }^{232}$ Sie verlegte sich stattdessen aufs „Verhindern“ und auf „Recherchen“ über die „Ausplünderungspolitik“ von Schweizer Firmen in Entwicklungsländern. Wie erwähnt, sollten sich diese „Recherchen“ aufgrund der Überschaubarkeit der Schweizer Investitionen in Entwicklungsländern durchaus als machbar erweisen.

Die implizite Alternative, welche die Bewegung der 1980er-Jahre präsentierte, war die Autarkie. Nicht alternative Wirtschafts- und Handelsmodelle sah sie für die Dritte Welt vor, sondern schlicht gar keine: „Wir sind der Meinung, dass jedes Land seinen eigenen Weg ohne ausländische Beeinflussung gehen soll. “233 Damit war die Ausgrenzung der „untersten Milliarde“, wie sie Paul Collier beschreiben sollte, aus dem Welthandel bereits zu Beginn der 1980er-Jahre für „linke Entwicklungspolitiker“ ideell unter dem Euphemismus des „eigenen Wegs“ besiegelt. ${ }^{234}$ Die zustimmend-unterstützende Haltung der Fair-Trade- und Dritte-WeltBewegung zum westlichen Protektionismus war nun intellektuell fundiert. Und dies nicht nur für den Agrarprotektionismus, sondern auch für die Überreste des Industrieprotektionismus, der in der Schweiz nicht einmal von bürgerlicher Seite gestützt wurde. ${ }^{235}$ So ist der Schwerpunkt auf die Landwirtschaft und den Kleinbauern im Manifest von 1981 noch nicht ersichtlich, wogegen sich ein eher sozialistischer Schwerpunkt auf den Arbeiter feststellen lässt: „Die Arbeiterinnen und Arbeiter in der Dritten Welt werden gezwungenermassen zu Lohndrückern der Arbeiterinnen und Arbeiter in der Schweiz." ${ }^{\text {236 }}$

In diesem Sinne erlebte das Nationale zu Beginn der 1980er-Jahre ein Comeback. $^{237}$ Die Umweltbewegung und die Bewegung, die nach dem Slogan Small is beautiful leben wollte und sich für biologische Landwirtschaft und Kleinbauern im Inland einsetzte, beförderte eine Moralisierung der einheimischen Wirtschaft als „natürlich“. Durch die durchaus reaktionär-konservative Biobewegung bekam die Aufforderung, inländische Produkte zu kaufen (das Begehren stammte aus den Zeiten der Wirtschaftskrise der 1930er-Jahre), einen neuen

232 SozArch, EvB, Ar 430.26.1. Mappe 2: Entwicklungspolitischen Manifest für die 80er Jahre, 1981.

233 SozArch, EvB, Ar 430.26.1. Mappe 2: Entwicklungspolitischen Manifest für die 80er Jahre, 1981.

234 C. W., „Soziale Befreiung“ gegen Entwicklungszusammenarbeit, NZZ, 29.5.1981.

235 R. Weder, S. Wyss: Do Vertical Linkages.

236 SozArch, EvB, Ar 430.26.1. Mappe 2: Entwicklungspolitischen Manifest für die 80er Jahre, 1981.

237 T. Scheidegger: Vom ,Schweizerbauern‘. 
Sinn. ${ }^{238} \mathrm{Zu}$ Beginn der 1980er-Jahre tauchte das Schweizer Kreuz etwa auf Unterlagen der Kleinbauern-Vereinigung auf und wurde von der Fair-Trade-Bewegung kommentarlos akzeptiert. Das „Unbehagen im Kleinstaat“ war einem moralisch fundierten Vorrang des Lokalen - und damit der Schweiz - gewichen, und einem Wohlbehagen in der Kleinheit, was faktisch dem Nationalismus Vorschub leistete. ${ }^{239}$

Für die Entwicklungsländer waren die tropischen, ehemals kolonialen Rohstoffe übriggeblieben, wobei - wie die Beispiele Bananen oder Zucker zeigen sogar diese kritisch hinterfragt wurden. ${ }^{240}$ Darauf hatte die OS3 bereits bei der Gründung fokussiert, darauf wollte sich die EvB nun in ihrer Wirtschaftspolitik konzentrieren. Die ursprüngliche Idee, dass diese Rohstoffe im Herkunftsland verarbeitet werden sollten, verschwand, und einzig die Kritik an den noch verbliebenen Rohstofffirmen der Schweiz blieb übrig.

238 O. Kühschelm: Sagen, Zeigen, Tun.

2391986 empfahl die EvB gar ein „JA“ zum Zuckerbeschluss, der von den Stimmberechtigten wuchtig verworfen wurde. Das „NEIN“ der Bevölkerung wurde als wichtige Richtungsweisung gegen die Überschusswirtschaft und für produktivitätsunabhängige Direktsubventionen gesehen. Die EvB hob sich damit sogar von den anderen schweizerischen Entwicklungsorganisationen ab. P. Moser: Stand der Bauern, 310.

240 K. J. Kuhn: Entwicklungspolitische Solidarität, 264, P. Moser: Stand der Bauern, 310. 